\title{
Impact of futures expiration on underlying stocks: intraday analysis for Warsaw Stock Exchange
}

\author{
Henryk Gurgul $^{1}$ (D) Milena Suliga ${ }^{1}$
}

Published online: 7 January 2019

(c) The Author(s) 2019

\begin{abstract}
Based on high-frequency data, this study is concerned with the effects of stock futures expirations on the spot market on the Warsaw Stock Exchange. The typical effects of futures expirations include the impact on the trading volume of the underlying asset, abnormally high volatility of the returns on expiration day, and price reversal after expiration. In line with observations of the effects for other markets, it can also be noticed that futures expiration is a source of rises in trading volume for the WSE. There is an observed significant abnormal trading volume and turnover of stocks that are underlying assets of futures as well as an increased volatility of these stocks' returns on expiration day. An additional analysis conducted during three sub-periods (around April 15, 2013, and May 31, 2015) checks whether the implementation of a new transaction system on the WSE and the changes in short-selling rules influenced the expiration-day effects. The results suggest that the implementation of a new regulation by the EU on the WSE concerning short selling in trading on stock exchanges had a significant impact on expiration-day effects.
\end{abstract}

Keywords Tick-by-tick data $\cdot$ Futures market - Expiration-day effects · Warsaw Stock Exchange

JEL Classification C32 · C14

Henryk Gurgul

henryk.gurgul@gmail.com

Milena Suliga

msuliga@zarz.agh.edu.pl

1 Department of Applications of Mathematics in Economics, Faculty of Management, AGH University of Science and Technology, ul. Gramatyka 10, 30-067 Kraków, Poland 


\section{Introduction}

There are two types of derivatives: commodity derivatives and financial derivatives. In our contribution, we are concerned with those financial derivatives whose values are derived from the prices (or price indices) of underlying securities. Futures contracts are derivatives that are similar to forward contracts; however, they are only traded on organized exchanges and are in standardized contract sizes.

Derivatives attract a great deal of attention from market participants and scholars. The important feature of these instruments is their settlement on expiration day.

The time of the cash settlement of financial derivatives has an impact on the market itself. This is also a source of price pressure with respect to the underlying assets. The impact of the expiration day of financial derivatives like stock or index futures contracts on the price, volatility, and volume of the underlying stocks has always been of special interest to academicians, investors, and regulators. The price, volatility, and trading volume are frequently distorted at a time close to the expiration moment due to speculative or arbitrage strategies on the stock and index futures.

The expiration-day effects of futures contracts have been detected in studies on stock markets, including those of the U.S., Canada, Germany, Sweden, Japan, India, and Australia (see, for example, Karolyi 1996; Schlag 1996; Stoll and Whaley 1997; Alkebäck and Hagelin 2004; Vipul 2005; Debasish 2010; Tripathy 2010; Narang and Vij 2013; Fung and Jung 2009; Illueca and Lafuente 2006; Chow et al. 2013; Mahalwala 2016).

The contributors of these studies were confronted with three typical expiration-day effects: the increase in trading volume of the underlying stock or index on expiration day, the increase in return volatility on expiration day, and the price reversal after expiration day. However, the effects differ across time, markets, and stocks because of the different sizes and microstructures of the markets under study.

One of the sources of the price, volatility, and volume distortion around expiration day is the unwinding of cash positions by arbitrageurs in cash markets. If many arbitragers unwind their positions in the same direction and the unwinding is unexpected, it can generate an unexpected imbalance in orders (Stoll and Whaley 1986) and price effects may occur (Stoll and Whaley 1997; Alkebäck and Hagelin 2004).

Early contributors Stoll and Whaley $(1986,1987,1991)$ detected an essential rise in the volumes of index stocks during the last hour of trading on quarterly expiration days for S\&P 500 (CME) futures contracts. The authors found evidence of a small reversal of the index half an hour after expiration day. Stoll and Whaley (1990) confirmed a similar price-reversal pattern even in non-index stocks (comp. Vipul 2005; Stoll and Whaley 1986, 1987) for U.S. index derivatives.

According to Stoll and Whaley (1991) and Vipul (2005), the "triple witching hour" is very important; that is, the last trading hour on the third Friday of the quarterly month when stock options, index futures, and index options expire simultaneously. In order to reduce the expiration-day effects, a number of solutions have been suggested from market regulators and market participants. One solution is to choose different expiration days for different contracts.

Besides arbitragers, the intended actions of speculators may also be a source of expiration-day effects. The final price of the contract is calculated on the basis of 
the underlying asset prices from expiration day. Therefore, speculators can try to manipulate the price in order to settle the contract at the best price from their point of view.

However, the actual price does not reflect the true value of an asset. If the Fama hypothesis of efficient markets holds true, the incorrectly priced asset becomes interesting for rational investors. As a result of their actions, the price without delay again reflects the intrinsic value of the stock. Therefore, the speculative changes of underlying assets on expiration days are usually of a temporal nature. This explains the price reversal phenomenon after an expiration day. Because of different initial expectations, different assessments of market situations, and different goals of particular groups of investors, expiration day may be a source of high trading volume as well as rising return volatility.

In general, speculative or arbitrage strategies cannot be successfully conducted on efficient and deep markets. Such markets can be manipulated by powerful market participants (from a financial point of view). Therefore, market speculation with respect to future contracts on a spot market may be successful on small emerging markets.

Based on intraday data, our study is concerned with expiration-day effects on the Warsaw Stock Exchange. It is the largest emerging stock market in the CEE region. As compared to other emerging stock markets or even the Vienna Stock Exchange, it is much more liquid. However, taking into account intraday data, we expect that the typical expiration-day effects for well-developed and efficient stock markets will be more visible on the WSE than what is reported for these markets in numerous papers.

The most important reason for choosing the WSE is the scarcity of research on expiration-day effects on the Warsaw Stock Exchange (Morawska 2004, 2007; Suliga 2017; Suliga and Wójtowicz 2019). The studies by Morawska (2004, 2007) were conducted in the initial period of the derivatives market in Poland with respect to WIG20 index futures while futures on individual stocks were omitted. This direction of research was undertaken by Suliga (2017); however, this was only with respect to price reversal.

The contribution by Suliga and Wójtowicz (2019) is concerned with the impact of derivatives on the spot market on the WSE with respect to all three expiration-day effects based on recent daily data.

This paper is based on intraday data. Using this data, we check the impact of single stock futures expiration on the trading volume, volatility, and prices of the underlying assets. We compare the results with the daily results from the WSE and from other markets as well as with the intraday results from foreign markets. The results are useful in the assessment of the degree of efficiency as well as the microstructure of the Polish stock market. The important goal of the paper is to also examine the joint dynamics of derivatives and spot markets in Poland. This may be important with respect to the proper settlement procedure on the futures market. This in turn may be essential in order to avoid an adverse influence of the derivative market on the spot market. In addition, our analysis during the sub-periods demonstrates changes of the expirationday effects on the WSE during the period under study. To the best of our knowledge, our paper is the first contribution on futures expiration effects based on intraday data in the CEE region. From this fact follows the added value of this paper. 
The structure of the paper is as follows. The next chapter enhances a review of the literature on expiration-day effects. The subsequent chapter presents the data, methodology, and main research hypotheses. Empirical results are presented and discussed in Chapter 4. Chapter 5 concludes the paper.

\section{Literature review}

The early empirical evidence on expiration-day effects was reported for U.S. derivatives markets (Stoll and Whaley 1987, 1990, 1991; Feinstein and Goetzmann 1988; Herbst and Maberly 1990; Hancock 1993; Chen and Williams 1994). These results confirm the abnormally high trading volume. In addition, one can see lower average returns in general on expiration days. From these studies follows the decline of the underlying stock prices; they do not tend to reverse at the next opening. These empirical findings are in favor of the statement that stock variables on expiration day do not exhibit a price pattern. The empirical results for other countries are mostly in line with the findings for U.S. stock exchanges (Pope and Yadav 1992; Karolyi 1996; Stoll and Whaley 1997; Corredor et al. 2001; Chow et al. 2003). The impact of expiration day on price volatility is unclear in the light of the literature. Stoll and Whaley (1990) and Hancock (1993) detected that, in the case of price settlement on the S\&P 500, a Friday opening on an expiration day was marked by a higher volatility in the spot market. In their next contribution, Stoll and Whaley (1997) detected a rise in volatility in individual stock returns on the Australian Stock Exchange. In the following contribution, Chow et al. (2003) found abnormal volatility on the Hang Seng Index. The increased volatility was calculated using one and five trading days before the expiration of their futures and options. Contrary to these findings, some early contributors did not find significant effects of the expiration day of futures contracts on volatility.

Among the first contributors from this stream of research were Pope and Yadav (1992). They studied all options expirations from October 1982 to September 1987 on the London Stock Exchange. Based on their findings, they did not reject the null hypothesis that the variance of stock returns during the event period is equal to the variance of the stock returns during the control period. As an event window, they defined the time interval spanning from 4 days before to 5 days after expiration day. Karolyi (1996) conducted his research with respect to the intraday return volatility of Japanese stocks. He defined an event window as the final trading hours of expiration days and the first hours following the expirations. He tested whether the volatility in the event window is equal to the intraday volatility during the same time span of non-expiration days (estimation window). His conclusion was that the intraday return volatilities do not essentially change.

As our research is focused on the volume and volatility effects of futures expirations, we conduct a further review in separate paragraphs in the following part of this chapter with respect to these two effects (after a short general overview of the literature). 


\subsection{Volume effects}

Volume effects have been investigated on several markets and also mostly confirmed on the spot markets of Germany (Schlag 1996), Sweden (Alkebäck and Hagelin 2004), India (Vipul 2005; Debasish 2010; Tripathy 2010; Narang and Vij 2013; Mahalwala 2016), Poland (Morawska 2007), China (Fung and Jung 2009), Spain (Illueca and Lafuente 2006), and Taiwan (Chow et al. 2013).

The contributors used different measures and definitions of trading volume. The results are not fully comparable because of the examined effects of the expirations of futures alone or the effects of the simultaneous expirations of futures and options. Schlag (1996) checked the impact of the expirations of options and futures on the DAX index during the period of September 1991 through December 1994. He established that, on quarterly expiration Fridays when futures and options expired simultaneously, the daily trading volume of stocks from the DAX was more than three times higher than on other Fridays. Taking into account that the number of shares traded was much lower on expiration days of options themselves, Schlag (1996) concluded that the observed volume effect was due to futures expirations.

Alkebäck and Hagelin (2004) followed Stoll and Whaley (1997) with respect to the measure for a control window (estimation window). They investigated the impact of the simultaneous expiration of futures and options on the Swedish OMX index between January 1988 and December 1998. They conducted their analysis during two subperiods; i.e., before and after the removal of the transaction tax in December 1991. Following Stoll and Whaley (1997), the detrended measures of the trading volume of all stocks from the OMX index for expiration days were compared with the same measures for the control period. The comparison was also conducted on a weekly basis. Alkebäck and Hagelin (2004) established that the trading volume was about $9 \%$ higher on expiration days with respect to control days (but also on earlier days of expiration weeks). According to the contributors, the source of this early increase in trading volume was the activity of arbitragers unwinding their positions on the spot and derivative markets before expiration. This activity should mitigate the ensuing risk from the final settlement price of the contract. In line with these findings are the results on the Indian market by Debasish (2010).

Some authors like Stoll and Whaley (1986), Illueca and Lafuente (2006) and Morawska (2007) reported intensified trading on the underlying assets of expiring derivatives during the final trading phase of an expiration day.

Analyzing the expiration-day effects of futures and options on the Chinese Hang Seng index during the period of January 1990 through December 1999, Chow et al. (2003) obtained results that were different than most of the findings in other markets. They did not observe the trading volumes on expiration days to be higher than on other days. The authors suggested that this difference might be attributable to the long settlement period of these contracts. However, after studying the expirations of futures on the Hang Seng index but during a different period of time (from May 1996 through May 2000) and with the use of high-frequency data, Fung and Jung (2009) came to the opposite conclusion: the trading volume and total trade counts were both higher than normal on expiration days. Moreover, they found that trading intensified around the 
5-min time marks. They argued that this was caused by the fact that the final settlement price of an HSI future is equal to the arithmetic average of the underlying index taken every $5 \mathrm{~min}$ on expiration day.

The comparison between the conclusions obtained by Chow et al. (2003) and Fung and Jung (2009) revealed that the results of the analysis of expiration-day effects can vary depending on both the period under study and the method of the research. Alkebäck and Hagelin (2004) suggested that the daily data may be unable to properly reflect the effects and, thus, the conclusions based on high-frequency data should be perceived as more reliable.

\subsection{Volatility effects}

Many contributors investigated both trading volume behavior and volatility behavior on the expiration days of derivatives. Most of them reported a rise in volatility on expiration days. This stream of research includes contributions for the U.S. (Stoll and Whaley 1986; Day and Lewis 1988; Diz and Finucane 1998), Australia (Stoll and Whaley 1997; Lien and Yang 2005), Canada (Chamberlain et al. 1989), Sweden (Alkebäck and Hagelin 2004), Spain (Illueca and Lafuente 2006), Poland (Morawska 2007), India (Narang and Vij 2013; Agarwalla and Pandey 2013), and Taiwan (Chow et al. 2013).

The earliest contribution on the matter was by Stoll and Whaley (1986) that featured two measures of index volatility (i.e., the standard deviation of the daily returns of an index and its absolute abnormal returns). They distinguished three types of days: the expiration of S\&P 500 futures, the expiration of CBOE options, and Fridays without expirations of derivatives. The authors found that the rise in volatility on expiration days could not be observed on a daily basis but was essential for intraday data (especially during the last 30 min of trading). The expiration of options did not solely imply an essential rise in volatility. A significant rise in volatility was visible only in the case of stocks listed on the S\&P 500 on the expiration days of S\&P 500 futures. In a more recent study, Alkebäck and Hagelin (2004) proposed a daily price range as a measure of volatility defined as the natural logarithm of the highest price divided by the lowest price on the day. The volatility effects by this measure were in line with the standard deviation of the daily returns. The authors detected a statistically significant rise in the volatility of the OMX index on expiration days only during the period of 1988-1991 (before the removal of the transaction tax).

To guarantee the comparability of different stocks, Vipul (2005) estimated daily volatility by a ratio of the difference between the maximum and minimum prices and their average. The author found no significant rise in the volatility of the underlying stocks as an effect of the expiration of futures and options on the Indian stock market between November 2001 and May 2004.

Using a measure of volatility similar to Vipul (2005) and based on index futures and options in Sweden, $\mathrm{Xu}$ (2014) also did not detect a statistically significant rise in volatility on expiration Fridays as compared to non-expiration Fridays.

Debasish (2010) studied the expiration-day effects of futures on the Indian NSE Nifty index during the period of June 2001 through May 2009 (additionally dividing 
the period under study into two subperiods). She used the daily price range as a measure of price volatility and estimated the range by taking the natural logarithm of the ratio of the daily high and daily low. The author found a rise in volatility only during the first subperiod; namely, between June 2001 and May 2005. After studying Ibex 35 futures expirations, Illueca and Lafuente (2006) discussed the importance of a volatility measure used to detect the existence of the volatility effect. In the first part of the research, they applied 15-min intraday returns to calculate the realized volatility of the index from the whole expiration day and from two subperiods of the day (the first covering the hours out of the settlement, and the second involving the hours around the settlement). They detected increased volatility only during the interval of time from which the settlement price of the contracts was calculated. In a further analysis, they employed daily close-to-close returns to show that the effect was not reflected in the daily data.

\subsection{Expiration-day effects on WSE}

The results of the studies reported below are based on daily data.

The expiration-day effects of futures on the shares and indices of the Warsaw Stock Exchange have been studied by Morawska (2004, 2007), Suliga (2017), and Suliga and Wójtowicz (2019). Morawska (2004, 2007) checked the impact of the expiration of WIG20 index futures on the returns of the index itself and on the trading volume of the stocks from it. She detected a rise in the trading volume of the stocks and in the volatility of the intraday returns of the index. However, she did not find a price reversal of the index returns after expiration. Morawska's focus on the WIG20 is justified; during those years, the volume of the futures on the WIG20 constituted more than $97 \%$ of the entire trading volume on the derivative market.

Suliga (2017) conducted her study on expiration days during the time period of 2001-2016. She also took the effects of futures on the mWIG40 as well as futures on individual stocks into consideration. Suliga (2017) checked the effect of price reversal after expiration by three different measures. The results supported the conjecture of price reversal in the stocks' returns after the expiration of the stock futures. However, no method supported the existence of the reversal in the WIG20 and mWIG40 returns. In a recent contribution based on the daily data for the WIG20, mWIG40, and individual stocks, Suliga and Wójtowicz (2019) conducted an extensive analysis of expirationday effects. Their study confirmed that, on the days of index futures expirations, abnormally high daily turnover and relative turnover values of the stocks from the index can be observed. In the case of single stocks that are underlying assets of stock futures, all three expiration-day effects were detected.

\subsection{Relationship between settlement price of futures contracts and expiration-day effects}

The results from research conducted on different foreign markets indicate that the situation on the market around expiration days (in particular, factors contributing to the price formation of futures contracts) determines the existence or absence of 
expiration-day effects. The actions of the investors depend on the way the settlement price of the contract is calculated.

Stoll and Whaley (1986) checked that, in the case of futures on the S\&P 500 Index and futures on the MMI Index (which were settled at a closing index level), the effects were concentrated over a very short period of time near the close. Illueca and Lafuente (2006) studied the expiration-day effects of futures on the Spanish Ibex35 Index that were settled on the arithmetic average index value between 16:15 and 16:45 (taking one value per minute). They detected volume and volatility effects during the interval of time from which the settlement price of the futures was calculated. Although the trading volume was higher on average on expiration Fridays than on control days, the greatest difference occurred within the final interval (in which trading volume was about $33 \%$ higher on expiration days than on control days). The conditional realized volatility of the index during this time interval was also slightly higher on expiration days as compared to non-expiration days.

Similar results were obtained on the Polish equity market by Morawska (2007), who studied the expiration-day effects of futures on the WIG20 index. The settlement price of these futures is based on the index values from the last hour of trading. She found that, during this subperiod of an expiration day, the volatility of stocks from the index was significantly higher than on the analogous subperiods of other Fridays.

Fung and Jung (2009) studied the expirations of futures on the Hang Seng Index, which are settled at an arithmetic average of the index taken every 5 min on expiration days. They found significant growth in the trading activity on the expirations. In particular, they checked that the trading intensified close to the 5-min time marks (both in volume and frequency). Although they found persistent order imbalances on expiration days, a price reversal after expiration was not detected.

A slightly different settlement procedure is applied in the case of futures and options on the Swedish OMX index. The settlement price is equal to the average volumeweighted value of the index of the last trading day. After studying the expiration-day effects of derivatives on the OMX Index, Alkebäck and Hagelin (2004) detected increased trading activity on expiration days and during expiration weeks. They suggested that this was a signal of the activity of arbitragers who unwound their positions on or before expiration days. However, they found no price distortion on the expirations. They argued that the long settlement period that is used to calculate the settlement price of index futures helped to curb sharp price movements. Thereby, the activity of arbitragers upon expiration failed to cause any price distortion. An analogous ascertainment was formulated by Debasish (2010), who studied the expiration-day effects of futures on the Indian NSE Nifty index. She also concluded that, because of the long settlement periods of these contracts, the unwinding of arbitrage positions failed to cause any price distortions at expiration. Another source of expiration effects is the activity of speculators who try to contribute to the settlement price. They can also potentially earn more in the case of essential price fluctuations. Alkebäck and Hagelin (2004) claimed that, when the settlement price is based on the intraday quotes of the underlying asset from the whole expiration day, the role of speculation in the formation of the settlement price may also be insignificant.

To check whether the settlement mechanism affects futures expiration-day effects, Hsieh and Ma (2009) compared the expirations of two types of index futures; namely, 
TAIEX futures and SGX TW futures. These contracts have the same underlying spot market, but their final settlement prices are calculated in a different way. The authors came to the conclusion that, to minimize the expiration-day effects, 'the average price is better than the opening price, which in turn is better than the closing price settlement'.

The abovementioned results from different markets suggest that expiration-day effects can be especially strong within the period that is used to calculate the settlement prices of futures contracts. The effects should be the weakest in the case of futures that are settled at an average price of the underlying asset from the whole expiration day.

The settlement price of individual stock futures that are traded on the WSE is equal to a multiple of the closing price of an underlying share. Thus, we expect that increased trading activity as well as strong price distortion may occur within both the last minutes of continuous trading and overtime. However, during the period under study, most of the analyzed shares were shares from the WIG20 Index. Since the stock futures and futures on the WIG20 index expire on the same day, the effects can result from both index futures and stock futures expirations. The settlement price of futures on the WIG20 is calculated as the arithmetic average of the values of continuous trading of the index from the last hour of trading and the value at close (after removing the fivehighest and five-lowest values). Thus, we expect to detect expiration effects within the whole last hour of continuous trading, not only within its last minutes.

\section{Data, methodology, and research hypotheses}

In this contribution, we prove the existence of the effect of rises in volume and rises in volatility on the expiration day of individual stock futures on the Warsaw Stock Exchange during the time period of January 2011 through March 2017. The used dataset is based on tick-by-tick data and includes the price, turnover value, and trading volume of the underlying stocks. Due to the quarterly expiration of futures on the WSE, there were 25 expiration days of stock futures within the given period. Table 1 presents a list of the futures under study along with information about the first expiration date included in the research and the number of expirations under study. We only take into account those stock futures with at least one opened position on expiration day. Futures with no opened positions on expiration day were excluded from the sample.

\subsection{Measures of expiration-day effects}

In the studies on the expiration-day effects reviewed above, one can find a number of measures of the expiration-day effects. In most cases, the authors suggest that we compare the values of these measures on expiration days as well as on appropriately defined control days. This stream of research originated in Stoll and Whaley (1986, 1987, 1991) and was used over the following years in Bollen and Whaley (1999), Alkebäck and Hagelin (2004), Morawska (2007), Hsieh (2009), Chay et al. (2013) and $\mathrm{Xu}$ (2014). Our study is also based on this methodology. 
Table 1 List of futures included in sample. Source Own elaborations based on data collected from www. gpwinfostrefa.pl

\begin{tabular}{lll}
\hline First expiration under study & Underlying asset (abbreviation) & Number of expiration days \\
\hline $2011-03-18$ & ACP, KGH, PEO, PGE, PGN, PKN, PKO, & 25 \\
& PZU, TPE & 24 \\
$2011-06-17$ & LTS & 23 \\
$2011-09-16$ & CDR & 22 \\
$2011-12-16$ & JSW, LWB & 15 \\
$2011-12-16$ & GTC & 21 \\
$2012-03-16$ & GPW & 15 \\
$2012-06-15$ & KER & 13 \\
$2012-06-15$ & BRS & 18 \\
$2012-09-21$ & SNS & 13 \\
$2014-03-21$ & OPL & 10 \\
$2014-03-21$ & ALR & 6 \\
$2015-12-18$ & ENA, ENG & 5 \\
$2016-03-18$ & BZW, CCC, CPS, MIL & 2 \\
$2016-12-16$ & ATT, ING, KRU, CIE, MBK & \\
\hline
\end{tabular}

This table includes basic information about stock futures under study. Abbreviations of underlying stocks are presented along with information about first expiration date included in research and number of expirations under study. Only stock futures with at least one opened position on expiration days were included in sample

\subsubsection{Trading activity}

Changes in trading volume on expiration days may be evaluated by the natural logarithm of turnover $V_{t}$ calculated during three subperiods of an expiration day: from the opening through the beginning of the last hour of the continuous trading phase, during the last hour of continuous trading, and during overtime.

In order to check the changes of $V_{t}$ on expiration days, its values during the subperiods of the expiration days are compared to those values in the corresponding subperiods of the control days (other Fridays). In addition to trading volume $V_{t}$, we also use turnover value $v_{t}$ as an approximation for trading activity.

\subsubsection{Volatility}

The effect of expiration days on stock price volatility can be tested by several measures based on the returns. The indicators of stock price volatility are the mean absolute deviations of the 5-min returns from the opening through the last hour of trading and during the last hour of continuous trading as well as the absolute values of the returns during overtime.

In order to confirm the empirical results calculated by the descriptive methods outlined above, we use the event study methodology. Therefore, we outline this methodology in the following section. 


\subsection{Event study methodology}

Besides the indicators given in the first section of this chapter, we also use the event study methodology to assess the expiration-day effects on the WSE. We use this methodology to study the impact of expiration day on the trading volume and volatility of the underlying assets. The general principles of this methodology are given in Dragota and Tlica (2014), Gurgul and Majdosz (2007) and Murg et al. (2016), for example.

For the expiration day of futures (the day of the event), we test the reaction of the volatility and trading activity measures for the underlying stock in the event window (i.e., on expiration day, before it, and thereafter). As is common in the event study methodology, we define the pre-event window (estimation window) and the event window. The event day (expiration day) is denoted by $t=0$. The event window begins 5 days before expiration and ends 2 days after it $(t=-5, \ldots, 2)$. The length of the event window is in line with suggestions by Alkebäck and Hagelin (2004) that the duration of expiration effects cover about a week before expiration day. This is the result of the early unwinding of arbitrage positions. According to the results from foreign markets, the only effect that can be expected after expiration is price reversal. Since we do not study the effect of price reversal in this study, we decided to include 2 days after expiration into the event window, as Suliga and Wójtowicz (2019) detected a significant distortion of the turnover value of stocks on the 2 days following futures expiration. The length of the estimation window should not overlap the previous event window. Taking into account that the futures on the WSE expire quarterly, the pre-event window in our study consists of 45 trading days $(t=-50, \ldots,-6)$. The effects of the futures expiration on the spot market is checked by testing the changes of trading volume, turnover value, and volatility around expiration day in order to establish the size of the deviation with respect to the benchmark (in the absence of the event). The test statistic is based on abnormal variables $A X_{i, t}$; i.e., centered variable $X_{i, t}$ with respect to $E\left(X_{i t}\right)$. This variable stands for the volatility and volume effects. The variable for the first effect is the natural logarithm of trading volume $\ln \left(V_{i, t}\right)$ as well as the natural logarithm of turnover value $\ln \left(v_{i, t}\right)$.

The expected values (benchmarks) of these variables are calculated in the estimation window. The simplest approximation (calculated in this study) of the expected value is the mean value in the estimation window.

Next, we employ the Kolari-Pynnönen test statistic in testing whether futures expiration significantly impacts the spot market. This statistic is based on the average abnormal variables in the event window. In the first step, we calculate the values of abnormal variable $A X_{i, t}$ in the event and pre-event windows for each event $i(i=1, \ldots, N)$ in the sample (a single event is an expiration of one stock futures contract). In the second step, these values are divided by their standard deviation from the pre-event window. The standardized abnormal variables are given by

$$
S A X_{i, t}=A X_{i, t} / S\left(A X_{i}\right)
$$

where 


$$
\begin{gathered}
S\left(A X_{i}\right)=\sqrt{\frac{1}{44} \sum_{t=-50}^{-6}\left(A X_{i, t}-\overline{A X}_{i}\right)^{2}} \\
\overline{A X}_{i}=\frac{1}{45} \sum_{t=-50}^{-6} A X_{i, t} .
\end{gathered}
$$

The results obtained by Alkebäck and Hagelin (2004) suggest that volatility and volume effects can occur on an expiration day or within an expiration week. Thus, we calculate the ratio of standardized abnormal variables $S A X_{i, t}$ and the cross-sectional standard deviation in the event window from $t=-5$ to $t=0$ in order to account for event-induced increase in volatility. In this way, we obtain the following adjusted standardized abnormal variables:

$$
S A X_{i, t}^{\prime}= \begin{cases}S A X_{i, t} & t=-50, \ldots,-6,1,2 \\ S A X_{i, t} / S\left(S A X_{t}\right) & t=-5, \ldots, 0\end{cases}
$$

$S\left(S A X_{t}\right)$ is the cross-sectional standard deviation of $S A X_{i, t}$ on the $t$ th day.

$$
S\left(S A X_{t}\right)=\sqrt{\frac{1}{N-1} \sum_{i=1}^{N}\left(S A X_{i, t}-\overline{S A X_{t}}\right)^{2}}
$$

$N$ stands for the number of events in the cluster. The null hypothesis of the no event effect for the given $t_{0}$ in the event window implies that $S A X_{i, t_{0}}^{\prime}$ are random variables with zero mean and unit variance. For each $t_{0} \in\{-5, \ldots, 2\}$ separately, we test the significance of the abnormal variables. We apply the standardized ranks given by

$$
U_{i, t}=\frac{\operatorname{rank}\left(S A X_{i, t}^{\prime}\right)}{46}-\frac{1}{2}
$$

$t \in \Omega=\left\{-50, \ldots,-6, t_{0}\right\}$ and $i=1, \ldots, N$, and $\operatorname{rank}\left(S A X_{i, t}^{\prime}\right)$ stands for the rank of $S A X_{i, t}^{\prime}$ within the vector of the adjusted standardized abnormal variables from the pre-event window and $S A X_{i, t_{0}}^{\prime}$. The null hypothesis is formulated as $E\left(U_{i, t_{0}}\right)=0$. In order to test this hypothesis, Kolari and Pynnönen (2001) formulated the following generalized rank test with test statistic $\tau_{\text {grank }}$ :

$$
\tau_{\text {grank }}=Z \sqrt{\frac{T-2}{T-1-Z^{2}}}
$$

where

$$
Z=\frac{\bar{U}_{t_{0}}}{S_{\bar{U}}}
$$




$$
\begin{aligned}
\bar{U}_{t_{0}} & =\frac{1}{N} \sum_{i=1}^{N} U_{i, t_{0}}, \\
S_{\bar{U}} & =\sqrt{\frac{1}{46} \sum_{t \in \Omega} \bar{U}_{t}^{2}} .
\end{aligned}
$$

Under the null hypothesis, the distribution of the $\tau_{\text {grank }}$ statistic converges to a $t$-Student distribution with 44 degrees of freedom under the assumption that sample size $N$ increases to infinity.

After the presentation of the data and methodology used in the context of determining the role of futures expiration for stocks, we will formulate a detailed research hypotheses in the next section. These are based on the results known in the literature or the preliminary results of our own computations.

\subsection{Research hypotheses}

This paper examines whether expiration effects occur on the Polish stock market in the case of intraday data. Taking into account the previous results on the effects on volatility and trading volume by the expirations of options or futures published by other contributors for the daily data described in the literature review, we can formulate basic research hypotheses with respect to intraday data.

The effect of a futures expiration day on turnover is widely documented in the literature (mainly for daily data). We expect that this observation will be reflected more in the high-frequency data. Therefore, we formulate our first conjecture:

Conjecture 1 The results of the literature reports and those obtained by us for highfrequency data support the thesis that the trading volume and values of turnover on expiration days are significantly greater as compared to the values originating from control days.

Taking into account the method of calculating the final settlement price of stock and index futures, we formulate the next conjecture:

Conjecture 2 On futures expiration days, a strong increase in the trading volume and turnover value of the underlying stocks takes place during the last hour of continuous trading and overtime.

Research conducted on foreign markets with the use of intraday data reveals that, for most stock markets, the biggest differences on the volatility of stock returns between expiration days and control days were observed during the period of time from which the stock prices were used to calculate the final settlement price of the futures. Taking this observation into account, we formulate a respective hypothesis:

Conjecture 3 Stock return volatility during both the last hour of trading and overtime is significantly greater on expiration days than on control days.

The next hypothesis on volatility effects concerns the strength of these effects on expiration days and their dependence on the time of day: 
Conjecture 4 On futures expiration days, the volatility of stock returns increases significantly above expectations. The strongest increase can be observed during both the last hour of continuous trading and overtime.

Finally, we will check the impact of the implementation of a new transaction system on the WSE on April 15, 2013, as well as the implementation of a new EU regulation on the WSE concerning the short selling in trading on stock exchanges starting on June 1, 2015, on the occurrence of the expiration-day effects of futures contracts.

As a more advanced and faster transaction system should facilitate carrying out the arbitrage and speculative strategies, we predict the following:

Conjecture 5 The implementation of a new transaction system on the WSE on April 15, 2013, has contributed to the intensification of futures expiration-day effects in terms of turnover and volatility.

In our opinion, the cessation of the additional special regulation of the rules for concluding short sale transactions on the WSE by the implementation of the EU directive on June 1, 2015, should reduce the expiration-day effects of futures. From that day, some short positions in futures can be replaced by the appropriate short positions in stocks, which could possibly reduce investor interest in futures. Moreover, arbitrage strategies with short positions in stocks were more available. Thus, unwinding the arbitrage positions in the same direction by most of the arbitragers on expiration days (resulting in expiration-day effects) was less probable. Thus, we formulate our final conjecture:

Conjecture 6 The expiration-day effects of stock futures have been significantly cushioned by the implementation of the new EU regulation on the WSE concerning short selling in trading on stock exchanges starting on June 1, 2015.

In the next chapter, we will prove these hypotheses, taking the intraday data into account.

\section{Empirical results}

We will test the impact of futures expiration separately on volume and on volatility. We start to check the volume effect of expiration.

\subsection{Empirical results of volume effect of expiration}

At the very beginning, we draw plots of the average cumulated turnover of companies on expiration days and control days to visualize the volume effect of futures expiration. Since the data originates from the period in which the length of the phase of continuous trading on the WSE was changed, it was impossible to present plots from a whole trading day. In order to show the average results from all expiration days and control days between January 2011 and March 2017, plots were drawn of the average turnover from the last $6 \mathrm{~h}$ of continuous trading and overtime. Therefore, the data comes from the following subperiods: 
(a) The hours of 11:20-17:20 for the data from the subperiod of January 1, 2011, through April 14, 2013, and the turnover from the overtime period (17:30-17:35).

(b) The hours of 10:50-16:50 for the data from the subperiod of April 15, 2013, through March 31, 2017, and the turnover from the overtime period (17:00-17:05).

The data from these subperiods was combined in one set due to the mapping of every 5-min value of turnover into the time remaining until closing. The titles of the plots are followed by the numbers of expiration days taken into account in this research (given in parentheses). In the research, only those expiration days when the numbers of opened positions were not zero were considered. The broken vertical lines mark the last hour of continuous trading.

The control days of the first type (Control Days I) are the first, second, and fourth Fridays of those months in which the contracts expire (March, June, September, and December). The control days of the second type (Control Days II) are the third Fridays of those months in which the stock futures do not expire.

Figure 1 presents 8 out of the 31 plots. In most of the plots on expiration days, we can notice a rise in the cumulated value of turnover during both the last hour of continuous trading and overtime (it is even more pronounced and more rapid). On both types of control days, the average cumulated turnover seems to grow almost linearly during the trading day.

It is important to notice that the expiration days of the stock contracts are the same as the expiration days of the WIG20 index contracts. During the time period under consideration, most of the shares which were underlying assets of stock futures were shares from the WIG20 index. Since the exercise price for futures on the WIG20 index is calculated as the average of the values of continuous trading of the index from the last hour of trading and the value at close (after removing the five-highest and five-lowest values), we can assume that the increase of investor activity during the last hour of trading is rather due to the expiration of futures on the WIG20 index than implied by the expiration of contracts on individual stocks. Additionally, the very strong rise in turnover during overtime is probably caused by the activity of investors with open positions in individual stock futures. This supposition follows from the fact that the settlement price of the stock futures depends solely on the price of the stocks of the company under study at the close of expiration day. It is true that, in setting the final price of a contract on the WIG20 index, the index level at the close is taken into account; however, the averaging procedure and removal of the extreme values results in the fact that the value at the close has a very limited impact on the final settlement price of the index contract.

After the visualization of the futures' expiration effects on the plots, we use the Mann-Whitney $U$ test to confirm or reject the established sample interdependencies.

\subsubsection{Mann-Whitney $U$ test: comparison of trading volume and turnover value of companies on expiration days and control days}

In the next step, we calculate the log-volume and log-turnover of stocks during three subperiods of expiration days and control days: from the opening to the beginning 
ACP (25)

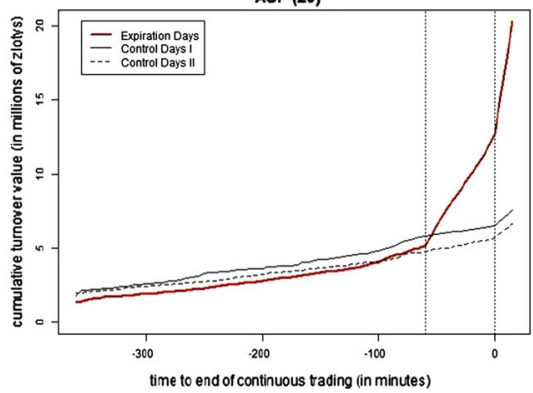

ENA (6)

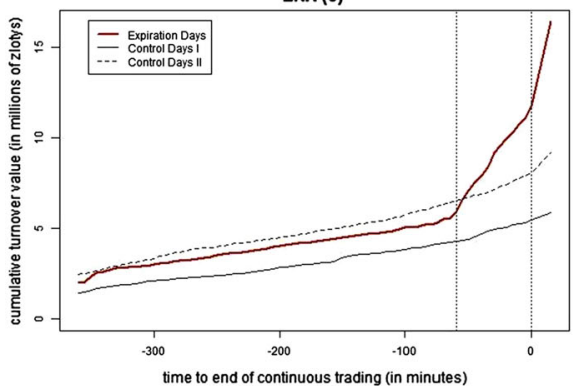

KER (15)

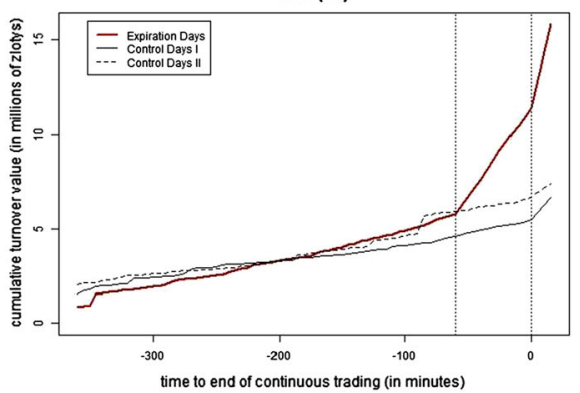

PKN (25)

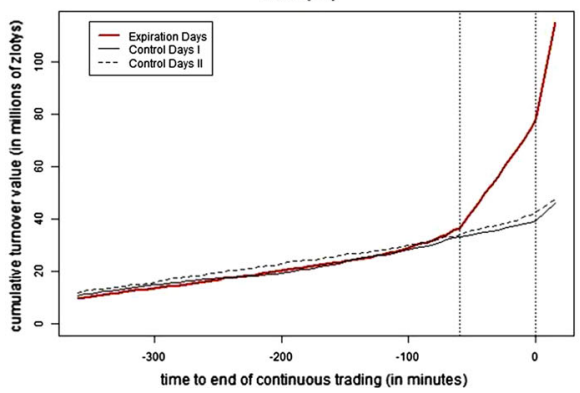

$\operatorname{ccc}(5)$

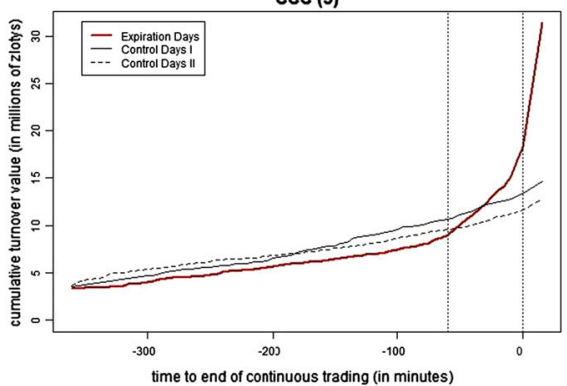

JSW (22)

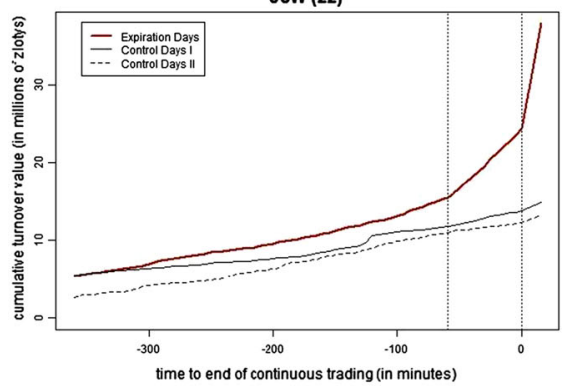

LTS (24)

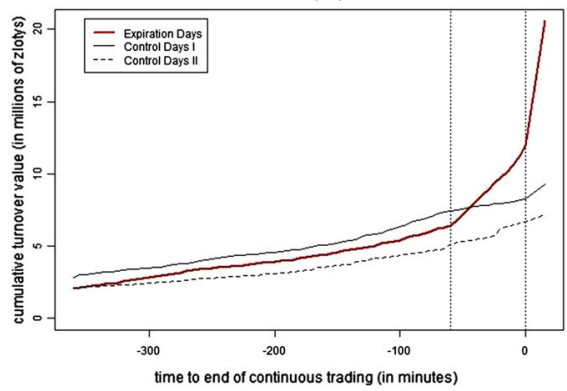

TPE (25)

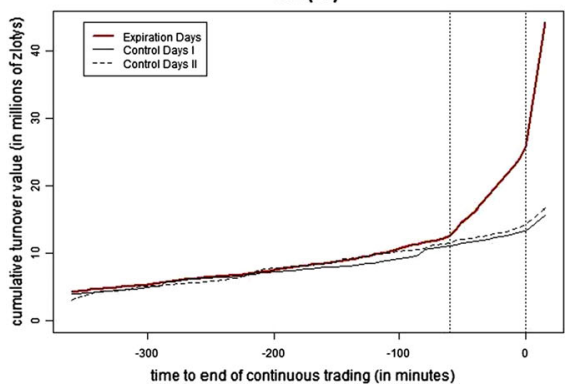

Fig. 1 Plots of cumulated turnover of companies on expiration days and control days. Source Own elaboration

of the last hour of the continuous trading phase, during the last hour of continuous trading, and during overtime. We compare the distribution of these values on the 
expiration days and control days with the use of a nonparametric Mann-Whitney $U$ test. The means and medians of the values as well as the $p$ values of the test are presented in Table 2. All of the calculated means and medians of the trading volume and turnover value are greater on expiration days than on both types of control days. The results from Panel A of the table indicate that the distribution of the cumulated turnover values from before the last hour of continuous trading on expiration Fridays is significantly different from their distribution on Control Days II (the third Fridays of the month without futures expirations). However, during this subperiod of a day, there is no difference between the distributions of trading volume. The $p$ values of the Mann-Whitney $U$ test presented in Panels B and C of the table confirm that, during the last hour of continuous trading and overtime, the means and medians of the logvolume and log-turnover are significantly greater on expiration days than on control days. The obtained results support the observations from the plots-trading activity is significantly greater on expiration Fridays as compared to other Fridays (especially during both the last hour of continuous trading and overtime).

The analysis of the trading volume and turnover value conducted with the use of the plots and Mann-Whitney $U$ test confirms Conjectures 1 and 2. The measures of the trading activity are significantly greater on expiration days than on control days, and the increase in trading volume and turnover value on expiration days appears during both the last hour of continuous trading and overtime. From Panel B of Table 2, it follows that, on average (in terms of geometric mean), the trading volume of stocks during the last hour of continuous trading on expiration days accounts for $470 \%$ (479\%) of the average trading volume from the last hour of trading on Control Days I (Control Days II). During overtime (see Panel C of Table 2), this difference is even more pronounced, as the average trading volume from expiration days is almost seven times higher than on the other Fridays of an expiration month and about seven-and-a-half times higher than on the third Fridays of those months without futures expiration.

A comparison with the results from other markets reveals that the impact of futures expirations on trading activity on the WSE is extremely strong. For example, Illueca and Lafuente (2006) checked that, within the last interval of trading (16:00-17:30) on the expiration days of Ibex35 futures between January 2000 and December 2002, the total volume of the stocks was $33 \%$ higher on average than during the same period of time on control days. Chow et al. (2013) studied the expiration-day effects of futures on the TAIFEX index. Starting in December 2008, the settlement price of these contracts was equal to the average price of the index during the 30 -min period prior to market closure on the final trading day. They found only a slight difference between the trading volume of stocks from this subperiod of expiration and non-expiration days. On average, this 30 -min trading volume accounted for $16.2 \%$ of the entire daily trading volume on settlement days, while this ratio was equal to $14.7 \%$ on control days. We calculated the analogous ratios, but we did not present the detailed results due to the lack of space in this paper. On the WSE, the sum of the trading volume from the last hour of continuous trading and overtime accounts for $61.9 \%$ on expiration days (on average), while on other Fridays, this was $28.1 \%$ (on Control Days I) and $28.6 \%$ (on Control Days II), respectively.

The results obtained with the use of daily data on other markets indicated the difference between the trading volume on expiration days and control days, ranging 
Table 2 Logarithms of joint values of trading volume and turnover value-comparison between expiration days and control days

\begin{tabular}{|c|c|c|c|c|c|c|}
\hline & \multicolumn{3}{|c|}{ Trading volume } & \multicolumn{3}{|c|}{ Turnover value } \\
\hline & Mean & Median & $p$ value & Mean & Median & $p$ value \\
\hline \multicolumn{7}{|c|}{ Panel A: from opening through last hour of listing ${ }^{\mathrm{a}}$} \\
\hline Expiration days & 12.399 & 12.574 & - & 16.193 & 16.199 & - \\
\hline Control Days I & 12.257 & 12.343 & 0.327 & 16.064 & 16.029 & 0.128 \\
\hline Control Days II & 12.254 & 12.351 & 0.197 & 15.997 & 15.939 & 0.016 \\
\hline \multicolumn{7}{|c|}{ Panel B: in last hour of continuous trading } \\
\hline Expiration days & 12.591 & 12.648 & - & 15.969 & 16.112 & - \\
\hline Control Days I & 11.043 & 11.108 & $\mathbf{0}$ & 14.429 & 14.438 & $\mathbf{0}$ \\
\hline Control Days II & 11.024 & 11.181 & $\mathbf{0}$ & 14.399 & 14.359 & $\mathbf{0}$ \\
\hline \multicolumn{7}{|c|}{ Panel C: in overtime } \\
\hline Expiration days & 12.39 & 12.525 & - & 15.883 & 16.09 & - \\
\hline Control Days I & 10.485 & 10.592 & $\mathbf{0}$ & 13.946 & 14.032 & $\mathbf{0}$ \\
\hline Control Days II & 10.369 & 10.522 & $\mathbf{0}$ & 13.814 & 13.981 & $\mathbf{0}$ \\
\hline $\mathrm{n}$ & 463 & & & & & \\
\hline
\end{tabular}

This table presents values of means and medians of log-volume and log-turnover of stocks on futures expiration days and on two types of control days: first, second, and fourth Fridays of expiration months (Control Days I) and third Fridays of months without futures expiration (Control Days II). Distribution of measures during three subperiods of day (from opening to beginning of last hour of continuous trading phase, during last hour of continuous trading, and during overtime) are compared between expiration days and control days with use of nonparametric Mann-Whitney $U$ test to verify whether there are significant differences. $p$ values of test are also presented in table

$p$ values smaller than 0.1 are in bold. Such values indicate that the distribution of the measure differs significantly between expiration days and control days at at least $10 \%$ level

${ }^{a}$ One should keep in mind that, until April 14, 2013, continuous trading took place during the period of 9:00-17:20; however, after this date, it took place during the period of 9:00-16:50. The research is conducted for data from 2011 to 2017; thus, the data from before the last hour of continuous trading comes from subperiods with different lengths

from several percentage points to a dozen or so (see Stoll and Whaley 1986; Alkebäck and Hagelin 2004; Fung and Jung 2009; Debasish 2010), which also confirms the unusual strength of the volume effect on the WSE.

The results presented in this section will be confirmed or denied by another approach; namely, an event study analysis.

\subsubsection{Event study analysis for log-volume and log-turnover of companies on expiration days}

The results presented above are based on a comparison between the trading activity on expiration Fridays and on other Fridays (control days). Now, we use the event study methodology to look at the issue of the impact of futures expiration on the spot market from a different perspective. As previously, log-volume and log-turnover are considered during three subperiods of a day. Their values during the event window (starting 5 days before expiration and ending 2 days after it) are compared with their 
'normal' values (defined as the average value from the estimation window). The preevent window contains 45 days just before the estimation window. The significance of the average abnormal values of the variables is tested with the use of a nonparametric Kolari-Pynnönen $\tau$-grank test. In Table 3, the values of the averages are presented with the values of the test statistic.

The left-most part of the table contains the averages of the abnormal log-volume and log-turnover from before the last hour of continuous trading. The test statistic values suggest that trading activity increases 1 day before expiration, as the averages on day $t=-1$ are significantly positive (at a $5 \%$ level). On an expiration day, the test statistics are positive but insignificant, which is a sign that investor activity before the last hour of continuous trading phase is not much different from that on other days. Negative and significant averages (at a 5\% level) on the day following expiration indicate that, immediately after expiration, the trading activity of investors on the stock market falls below its usual level. The results obtained for the values calculated during the last hour of continuous trading and overtime are presented in the middle and right parts of the table. All of the averages observed on expiration day are significantly positive at a $1 \%$ level, indicating that trading activity rose much more than expected. On the day before expiration, an increase in investor activity can also be noticed during overtime. One day after expiration, all of the averages are negative, suggesting a decrease in the trading activity on the spot market on the Mondays following expiration and also at the end of the trading session. However, only the averages from the last hour of continuous trading are significantly different from zero.

The results of the event study analysis of the volume effect confirm the previous observations from the plots and classical measures and additionally warrant the truth of Conjecture 2. The expiration of stock futures is accompanied by a significant rise in trading activity on the spot market. This rise is particularly strong during the period of time from which the stock prices are used to calculate the final settlement prices of the futures.

The effects of expiration reported in some of the contributions reviewed in the second chapter are reflected in the volatility. However, the authors are not unique in their opinion concerning the role of expiration with respect to volatility. Therefore, it is very interesting to prove the existence of this link on the Warsaw Stock Exchange (which will be done in the next section).

\subsection{Empirical results of volatility effect}

Similar to the research on the volume effect, we began the analysis of the volatility effect by drawing the appropriate plots. Figure 2 presents some sample plots of the average absolute values of the 5-min returns on expiration days and control days. As previously, to visualize the data from two periods with different lengths of the phase of continuous trading on the WSE on one plot, the returns from the last $6 \mathrm{~h}$ of continuous trading and from overtime were combined in one set and presented on the same terms as in the case of the plots of turnover value. In most of the plots, we can notice a rapid rise in the average return volatility during overtime as compared to the average volatility during the continuous trading phase (both on expiration days and 


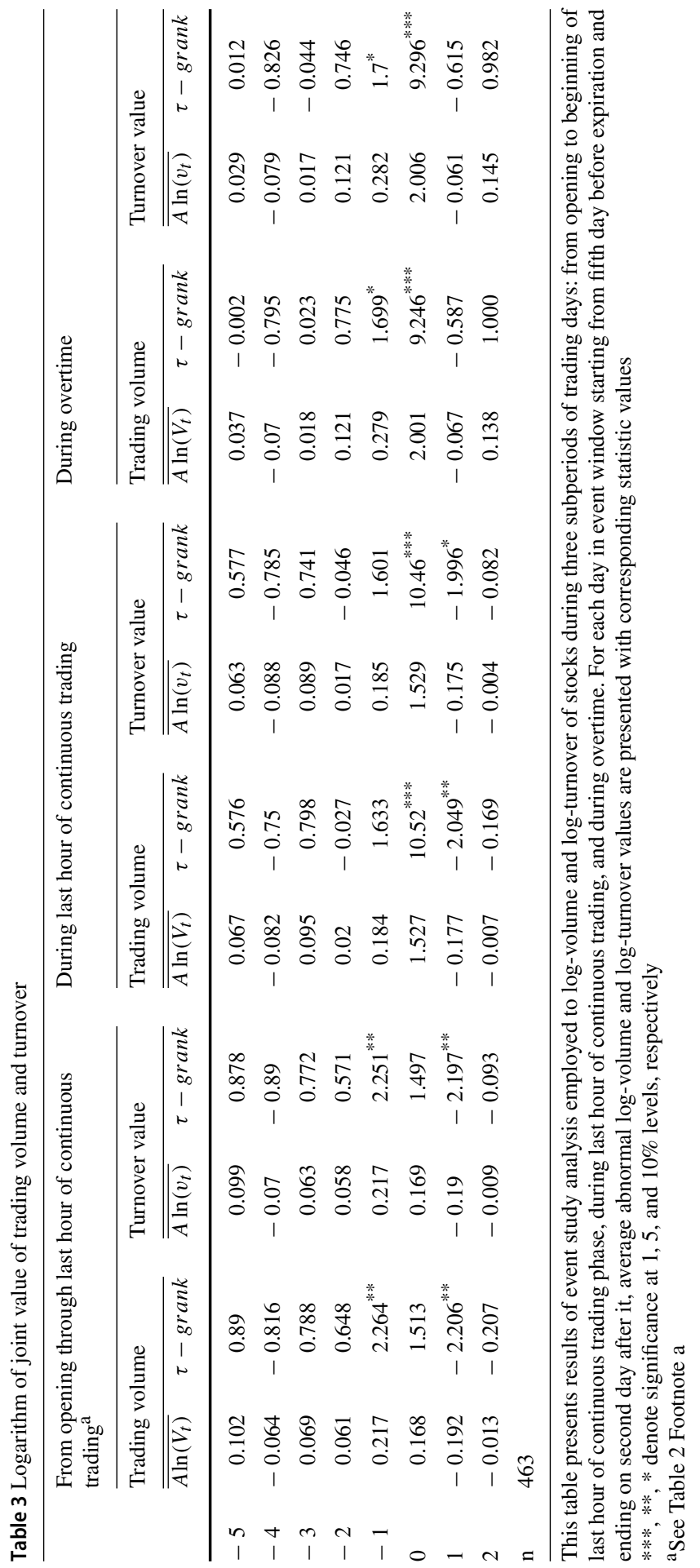



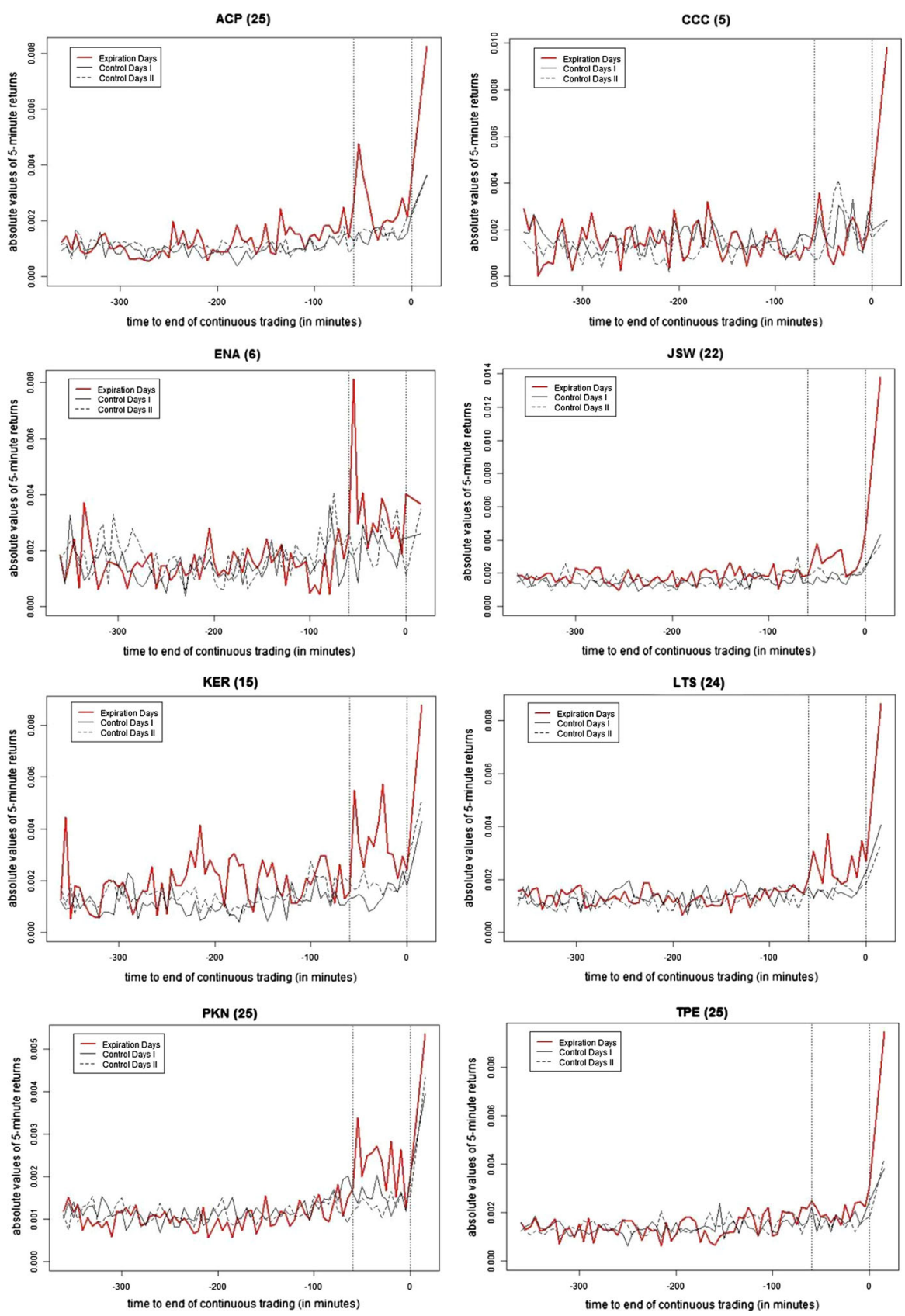

Fig. 2 Plots of absolute values of 5-min returns of stocks on expiration days and control days. Source Own elaboration

control days). The average overtime volatility that is greater than that of the phase of continuous trading seems to be a stylized fact. It is clear that returns from overtime exhibits other properties than the 5-min returns from the phase of continuous trading. 
However, in the case of 22 plots, this rise is essentially greater on expiration Fridays than on control days. This observation may confirm the fact of an additional rise in return volatility on expiration days of stock futures. In addition, on the number of plots, one can see that the averages of the absolute 5-min returns during the last hour of continuous trading on expiration days are greater than on control days.

As stressed in Sect. 4.1, the stock futures expire simultaneously with the WIG20 index futures; during the period under study, most of the individual shares, that are underlying assets of stock futures, constituted the WIG20 index. Taking into account the method of calculating the final settlement price of futures, we can assume that the increased volatility during the last hour of continuous trading can follow from the increase of investor activity caused by the expiration of futures on the WIG20 index, while the additional very strong rise in volatility during overtime is probably caused by the activity of investors with open positions in individual stock futures.

Analogous to the trading volume and turnover tests, we used the Mann-Whitney $U$ test with respect to volatility for the second part of our data.

\subsubsection{Mann-Whitney $U$ test: comparison of volatility of returns on expiration days and control days}

Table 4 contains the results of the comparison of return volatility between expiration days and control days. The means and medians of the volatility measures are presented with the $p$ values of the Mann-Whitney $U$ test.

The distribution of mean deviation of the 5-min returns from before the last hour of continuous trading on expiration days does not differ significantly from those observed on control days (as can be noticed in Panel A of the table). The results of the analysis of the mean deviation of 5-min returns during the last hour of continuous trading are presented in Panel B. The mean and median of the mean deviation are greater on expiration days than on both types of control days, and the $p$ values of the test are equal to zero. This is strong evidence that, during this subperiod, volatility is significantly higher on the days of futures expirations. The results of the analysis of the absolute values of returns during overtime are contained in Panel C. Just like in the previous subperiod, the volatility on expiration days is essentially greater during overtime. The results support the observation based on the plots and confirm Conjecture 3-a clearcut difference between the return volatility on expiration days and control days is observed, both during the last hour of trading and overtime.

The volatility effect of futures expiration on the WSE seems to be strong when it is compared with the results from other markets. The most similar results were obtained by Agarwalla and Pandey (2013), who studied the effects of single stock futures expirations on the Indian equity market between January 2001 and December 2009. The settlement prices of the researched contracts were equal to the volumeweighted spot prices of the underlying stocks from the last half hour of trading on expiration days. They found that the volatility of the returns increased on expiration days, but only during the last half hour of a trade (not during the other time intervals). Studying the expiration-day effects of futures on the Ibex35 Index on the Spanish equity market, Illueca and Lafuente (2006) detected only a slight difference in return volatility between expiration and non-expiration days. For the trading interval around 
Table 4 Volatility of returns - comparison between expiration days and control days

\begin{tabular}{lccc}
\hline & Mean (in \%) & Median (in \%) & $p$ value \\
\hline $\begin{array}{l}\text { Panel A: mean deviation of 5-min returns from opening to last hour of } \\
\text { continuous trading }^{\mathrm{a}}\end{array}$ & & \\
Expiration days & 0.159 & 0.137 & - \\
Control Days I & 0.165 & 0.134 & 0.969 \\
Control Days II & 0.152 & 0.131 & 0.113 \\
Panel B: mean deviation of 5-min returns during last hour of & & \\
continuous trading & & & - \\
Expiration days & 0.239 & 0.201 & $\mathbf{0 . 0 0 0}$ \\
Control Days I & 0.17 & 0.148 & $\mathbf{0 . 0 0 0}$ \\
Control Days II & 0.167 & 0.137 & - \\
Panel C: absolute values of returns during overtime & & $\mathbf{0 . 0 0 0}$ \\
Expiration days & 0.733 & 0.51 & $\mathbf{0 . 0 0 0}$ \\
Control Days I & 0.38 & 0.234 & \\
Control Days II & 0.32 & 0.224 & \\
$\mathrm{n}=463$ & & &
\end{tabular}

This table presents values of means and medians (in percentages) of measures of return volatility on futures expiration days as well as two types of control days: first, second, and fourth Fridays of expiration months (Control Days I) and third Fridays of months without futures expiration (Control Days II). For each group of days, mean deviation of 5-min returns from opening to last hour of continuous trading, mean deviation of 5-min returns during last hour of continuous trading, and absolute values of returns during overtime are calculated. Distributions of measures are compared between expiration days and control days with use of nonparametric Mann-Whitney $U$ test. $p$ values of test are also presented in table

$p$ values smaller than 0.1 are in bold. Such values indicate that the distribution of the measure differs significantly between expiration days and control days at at least $10 \%$ level

${ }^{\mathrm{a}} \mathrm{See}$ Table 2 Footnote a

expiration, the null hypothesis that spot return volatility was equal to that of nonexpiration days could be rejected only at a $10 \%$ significance level. For the other subperiods of expiration and control days, they found no difference in return volatility. Studying the volatility effect on the Taiwan stock market on the days when the futures on the TAIFEX expired, Chow et al. (2013) did not find any statistically significant difference between the return volatility on expiration days and on non-expiration days, even during the subperiod of the day from which the returns were used to determine the settlement price.

We use now an event study analysis in order to confirm the hypotheses with the use of another research method.

\subsubsection{Event study analysis for volatility of companies on expiration days}

The results of the analysis of volatility effect obtained with the use of event study methodology are included in Table 5. The left and middle parts of the table present the means of the abnormal mean deviation of the 5-min returns (from the opening to the last hour of continuous trading and during the last hour of continuous trading, respectively) with the corresponding value of the $\boldsymbol{\tau}$-grank test statistic. On the right 
Table 5 Return volatility

\begin{tabular}{|c|c|c|c|c|c|c|}
\hline & \multicolumn{2}{|c|}{$\begin{array}{l}\text { From opening through last } \\
\text { hour of continuous trading }\end{array}$} & \multicolumn{2}{|c|}{$\begin{array}{l}\text { During last hour of } \\
\text { continuous trading }\end{array}$} & \multicolumn{2}{|c|}{ During overtime } \\
\hline & $\overline{A S_{t}}$ & $\tau-$ grank & $\overline{A S_{t}}$ & $\tau-\operatorname{grank}$ & $\overline{A\left|R_{t}\right|}$ & $\tau-$ grank \\
\hline-5 & 0.008 & $2.645^{* *}$ & 0.003 & 1.187 & -0.013 & 0.952 \\
\hline-4 & 0.006 & $2.093^{* *}$ & 0.009 & 1.441 & 0.097 & $3.823^{* * *}$ \\
\hline-3 & 0.003 & 1.519 & 0.009 & $1.945^{*}$ & -0.062 & 0.27 \\
\hline-2 & -0.005 & 0.707 & -0.002 & -0.092 & -0.012 & -1.107 \\
\hline-1 & 0.006 & $2.314^{* *}$ & 0.019 & $2.643^{* *}$ & 0.139 & $4.448^{* * *}$ \\
\hline 0 & 0.006 & $2.255^{* *}$ & 0.073 & $6.894^{* * *}$ & 0.298 & $8.006^{* * *}$ \\
\hline 1 & 0.000 & 1.347 & 0.001 & -0.074 & 0.051 & 0.209 \\
\hline 2 & -0.006 & -0.3 & 0.002 & 0.645 & 0.201 & $2.469^{* *}$ \\
\hline
\end{tabular}

This table presents results of event study analysis employed to mean deviation of 5-min returns from before last hour of continuous trading, mean deviation of 5-min returns during last hour of continuous trading, as well as to absolute values of returns during overtime. For each day in event window starting from fifth day before expiration and ending on second day after it, average abnormal values of variables are presented with corresponding statistic values

$* * *, * *, *$ denote significance at 1,5 , and $10 \%$ levels, respectively

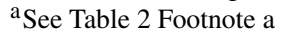

part of the table, the means of the abnormal absolute returns from overtime are included (also with the statistic values of the Kolari-Pynnönen test).

The results suggest that the volatility of the returns significantly increases above expectations on expiration day. The strongest increase can be observed during the last hour of continuous trading and overtime, which is a confirmation of Conjecture 4. One day before expiration, the volatility is increased during the continuous trading phase and overtime, as all of the test statistic values are significantly positive (at a 5\% level at least). On most of the days before the expiration included in the event window, there are also significantly positive test statistic values during the continuous trading phase and overtime. Only on day $t=-2$ are all of the test statistics insignificant. The growth of volatility before expiration can be a confirmation of the thesis formulated by Stoll and Whaley (1986) that expiration effects can occur over the week before expiration. The reason for this is the early unwinding of arbitrage positions (Alkebäck and Hagelin 2004). In Table 5, there is one significantly positive value of the test statistic after expiration; namely, the mean abnormal absolute return during overtime on day $t=2$. It is difficult for the authors to interpret this value by relating it with futures expiration. A more detailed study (whose results are presented in the following part of the article) will give some more insight into this matter.

In order to check whether the occurrence and strength of the expiration-day effects changed over time, we again apply the methodology outlined above during the properly chosen subperiods in the next section. At the very beginning, we aimed to check the volume effects during these subperiods (employing the $U$ test and then the event study approach). 


\subsection{Results of analysis conducted during subperiods: volume effect of expiration days}

To refine our study on stock futures' expiration-day effects and to check whether the impact of futures expiration on stocks changed over time, we decided to conduct our research additionally during three subperiods: January 2, 2011, through April 14, 2013; April 15, 2013, through May 31, 2015; and June 1, 2015, through March 31, 2017. The time frames for the subperiods were determined by the research question concerning the impact of the two events on the occurrence of expiration effects. The events are defined as follows:

(1) Implementation of a new transaction system on the WSE on April 15, 2013;

(2) Implementation of a new EU regulation on the WSE on June 1, 2015, concerning short selling in trading on stock exchanges.

\subsubsection{Mann-Whitney $U$ test: comparison of trading activity on expiration days and control days}

The existence of the volume effect during each of the subperiods is confirmed by the comparison of turnover reported in Table 6. The trading activity on expiration days is significantly greater than on both types of control days during the last hour of continuous trading and overtime. Furthermore, the results presented in Panel A of the table suggest that, during the first and second subperiods, the turnover value from before the last hour of continuous trading on expiration Fridays was similar to the other Fridays of the expiration month (Control Days I) but higher than on the third Fridays of those months without expiration (Control Days II). This difference is more pronounced during the second subperiod, where the appropriate $p$ value of the Mann-Whitney $U$ test is equal to 0.034 . The analysis of trading volume (not presented in this article) leads to the analogous conclusions. The results obtained during each of the subperiods are in line with the previous results presented in Table 2.

\subsubsection{Results of event study analysis}

The event study analysis (Table 7) also confirms that single stock futures expirations had an impact on the turnover of the underlying stocks during each of the researched subperiods. However, the strength of the impact changes over time. During the first subperiod, the averages of the instances of abnormal turnover are significantly positive during both the last hour of continuous trading on expiration days and overtime (at a $1 \%$ level). One day before expiration, the average turnover values are positive and significant (at a 10\% level) before the last hour of trading. One day after expiration, all of the calculated averages are negative (suggesting a decrease in trading activity); however, only the averages from the last hour of continuous trading are significantly different from zero (at a 5\% level). After the implementation of the new transaction system on the WSE on April 15, 2013, the volume effect of expiration seemed to intensify (as was assumed in Conjecture 5). During each of the subperiods of an expiration day and on the previous day, the turnovers are significantly higher than expected (at 
Table 6 Logarithms of total turnover value-comparison between expiration days and control days

\begin{tabular}{|c|c|c|c|c|c|c|c|c|c|}
\hline & \multicolumn{3}{|c|}{ Subperiod 1} & \multicolumn{3}{|c|}{ Subperiod 2} & \multicolumn{3}{|c|}{ Subperiod 3} \\
\hline & Mean & Median & $p$ value & Mean & Median & $p$ value & Mean & Median & $p$ value \\
\hline \multicolumn{10}{|c|}{ Panel A: from opening through last hour of listing ${ }^{a}$} \\
\hline Expiration days & 16.503 & 16.603 & - & 16.183 & 16.221 & - & 15.983 & 16.009 & - \\
\hline Control Days I & 16.427 & 16.43 & 0.505 & 15.956 & 15.896 & 0.21 & 15.888 & 15.906 & 0.434 \\
\hline Control Days II & 16.27 & 16.299 & 0.09 & 15.845 & 15.701 & 0.034 & 16.019 & 16.035 & 0.734 \\
\hline \multicolumn{10}{|c|}{ Panel B: during last hour of continuous trading } \\
\hline Expiration days & 16.428 & 16.646 & - & 15.942 & 16.125 & - & 15.668 & 15.753 & - \\
\hline Control Days I & 14.579 & 14.519 & $\mathbf{0}$ & 14.421 & 14.512 & $\mathbf{0}$ & 14.324 & 14.303 & $\mathbf{0}$ \\
\hline Control Days II & 14.606 & 14.543 & $\mathbf{0}$ & 14.201 & 14.238 & $\mathbf{0}$ & 14.702 & 14.732 & $\mathbf{0}$ \\
\hline \multicolumn{10}{|c|}{ Panel C: during overtime } \\
\hline Expiration days & 16.135 & 16.478 & - & 15.823 & 16.27 & - & 15.755 & 15.635 & - \\
\hline Control Days I & 14.36 & 14.479 & $\mathbf{0}$ & 13.953 & 14.181 & $\mathbf{0}$ & 13.633 & 13.778 & $\mathbf{0}$ \\
\hline Control Days II & 14.054 & 14.367 & $\mathbf{0}$ & 13.725 & 14.048 & $\mathbf{0}$ & 14.103 & 14.184 & $\mathbf{0}$ \\
\hline $\mathrm{n}$ & 130 & & & 148 & & & 185 & & \\
\hline
\end{tabular}

This table presents values of means and medians of log-turnover of researched stocks on futures expiration days and on two types of control days: first, second, and fourth Fridays of expiration months (Control Days I) and third Fridays of months without futures expiration (Control Days II). The research was conducted during three subperiods: January 2, 2011, through April 14, 2013 (Subperiod 1); April 15, 2013, through May 31, 2015 (Subperiod 2); and June 1, 2015, through March 31, 2017 (Subperiod 3). Distribution of measures on expiration days and control days are compared with use of nonparametric Mann-Whitney $U$ test to verify whether there are significant differences between them. $P$ values of test are also included in table

$p$ values smaller than 0.1 are in bold. Such values indicate that the distribution of the measure differs significantly between expiration days and control days at at least $10 \%$ level

${ }^{a}$ One should keep in mind that, until April 14, 2013 (during Subperiod 1), continuous trading took place during the time period of 9:00-17:20; however, after this date, it took place during the time period of 9:00-16:50

a $10 \%$ level at least). At the beginning of the Mondays following expiration, trading activity decreased below the expectations, which is reflected in the negative (and significant - at a 5\% level) average turnover. It should be noticed that all of the averages calculated for day $t=1$ are negative (during each of the subperiods and every time period of a day under study), suggesting a drop in activity after futures expiration. However, only some of them are significantly different from zero. During the third subperiod, a significant abnormal increase in turnover is observed only on the day of expiration and solely during both the last hour of trading and overtime. The other averages of abnormal log-turnover during the event windows are insignificant except for the negative average from the last hour of trading on day $t=1$. This indicates that the change in the rules concerning the short sale of stocks has attenuated the volume effect of futures expiration, which confirms one part of Conjecture 6.

The event study analysis performed for the log-volume (not presented here due to the lack of space) delivers results that are analogous to those obtained in the case of the log-turnover itself. 
Table 7 Logarithm of joint value of turnover

\begin{tabular}{|c|c|c|c|c|c|c|}
\hline & \multicolumn{2}{|c|}{ Subperiod 1} & \multicolumn{2}{|c|}{ Subperiod 2} & \multicolumn{2}{|c|}{ Subperiod 3} \\
\hline & $\overline{A \ln \left(v_{t}\right)}$ & $\tau-$ grank & $\overline{A \ln \left(v_{t}\right)}$ & $\tau-$ grank & $\overline{A \ln \left(v_{t}\right)}$ & $\tau-$ grank \\
\hline \multicolumn{7}{|c|}{ Panel A: from opening through last hour of continuous trading ${ }^{a}$} \\
\hline-5 & 0.234 & 1.505 & 0.039 & 0.35 & 0.053 & 0.359 \\
\hline-4 & -0.14 & -0.937 & -0.006 & -0.384 & -0.073 & -0.781 \\
\hline-3 & 0.115 & 1.165 & 0.12 & 0.871 & -0.019 & 0.059 \\
\hline-2 & 0.174 & 1.225 & 0.084 & 0.882 & -0.045 & -0.465 \\
\hline-1 & 0.237 & $1.824^{*}$ & 0.337 & $2.76^{* * *}$ & 0.107 & 1.084 \\
\hline 0 & 0.223 & 1.618 & 0.27 & $1.68^{*}$ & 0.05 & 0.571 \\
\hline 1 & -0.199 & -1.639 & -0.23 & $-2.082^{* *}$ & -0.152 & -1.527 \\
\hline 2 & 0.022 & 0.252 & -0.039 & -0.574 & -0.007 & 0.108 \\
\hline \multicolumn{7}{|c|}{ Panel B: during last hour of continuous trading } \\
\hline-5 & 0.148 & 0.956 & 0.097 & 0.639 & -0.024 & -0.193 \\
\hline-4 & -0.29 & $-1.729^{*}$ & 0.101 & 0.699 & -0.097 & -0.883 \\
\hline-3 & 0.146 & 0.758 & 0.082 & 0.223 & 0.056 & 0.7 \\
\hline-2 & 0.032 & 0.171 & 0.088 & 0.384 & -0.05 & -0.596 \\
\hline-1 & 0.189 & 1.174 & 0.382 & $2.266^{* *}$ & 0.023 & 0.224 \\
\hline 0 & 1.858 & $7.879^{* * * *}$ & 1.592 & $7.399^{* * *}$ & 1.247 & $8.254^{* * * *}$ \\
\hline 1 & -0.258 & $-2.039^{* *}$ & -0.087 & -0.705 & -0.186 & $-1.956^{*}$ \\
\hline 2 & 0.033 & -0.053 & -0.103 & -1.161 & 0.05 & 0.92 \\
\hline \multicolumn{7}{|c|}{ Panel C: during overtime } \\
\hline-5 & 0.123 & 0.262 & 0.088 & 0.242 & -0.085 & -0.365 \\
\hline-4 & -0.34 & -1.676 & 0.038 & -0.283 & 0.011 & -0.301 \\
\hline-3 & 0.054 & -0.065 & 0.004 & -0.037 & 0.000 & -0.008 \\
\hline-2 & 0.133 & 0.405 & 0.159 & 0.927 & 0.083 & 0.414 \\
\hline-1 & 0.26 & 1.597 & 0.405 & $1.983^{*}$ & 0.201 & 0.484 \\
\hline 0 & 1.963 & $8.671^{* * * *}$ & 1.971 & $5.49^{* * *}$ & 2.065 & $6.751^{* * * *}$ \\
\hline 1 & -0.155 & -1.029 & -0.021 & -0.374 & -0.027 & -0.24 \\
\hline 2 & 0.139 & 0.872 & 0.042 & 0.068 & 0.231 & 1.172 \\
\hline $\mathrm{n}$ & 130 & & 148 & & 185 & \\
\hline
\end{tabular}

This table presents results of event study analysis employed to log-turnover of stocks during three subperiods: January 2, 2011, through April 14, 2013 (Subperiod 1); April 15, 2013, through May 31, 2015 (Subperiod 2); and June 1, 2015, through March 31, 2017 (Subperiod 3). For each subperiod, analysis is conducted during three time spans of trading day: from opening to beginning of last hour of continuous trading phase, during last hour of continuous trading, and during overtime. For each day in event window starting from fifth day before expiration and ending on second day after it, average abnormal log-turnover values are presented with corresponding statistic values

$* * *, * * *$ denote significance at 1,5 , and $10 \%$ levels, respectively

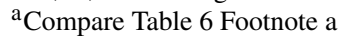


The effects of stock futures expiration on the WSE during the subperiods was investigated by Suliga and Wójtowicz (2019) with the use of daily data. They analyzed four subperiods: January 2001 through December 2009; January 2010 through March 14, 2013; March 15, 2013, through May 31, 2015; and June 2015 through December 31, 2016. Their results are consistent with ours: the volume effect was detected during each of the subperiods. Classical measures of the effect did not reveal significant differences in the strength of the effect among the subperiods; however, the results from the event study analysis suggested that this effect was strongest during the third subperiod, as a turnover value significantly higher than expected was also detected (at a $5 \%$ level) on the day before expiration.

After a thorough analysis of the volume effects of futures, we will conduct an analogous analysis with respect to volatility.

\subsection{Results of analysis conducted during subperiods: volatility effect}

\subsubsection{Mann-Whitney $U$ test: comparison of volatility of returns on expiration days and control days}

The results in Table 8 indicate the increased volatility of stock returns during the trading session. As in the case of the volume effect, the volatility effect also seems to be strongest during the second subperiod (which supports the theses included in Conjectures 5 and 6). It can be noticed in Panel A of the table that the distribution of the mean deviation of the 5-min returns from before the last hour of trading differ significantly between expiration days and control days only between March 15, 2013, and May 31, 2015. During the other sub-periods (the first and third sub-periods), these differences are insignificant; in most cases, the means and medians of the researched measures of volatility are even lower on expiration days than on those Fridays without expirations. However, the results from Panels B and C suggest that, during each of the subperiods, the volatility effect of futures expiration can be observed during the last hour of trading and overtime. The highest values of the means and medians of the volatility measures occur during the second subperiod, which is additional evidence that the volatility effect was strongest during this time span.

Similar research was conducted by Suliga and Wójtowicz (2019) on daily data; however, they detected statistically significant differences (at a $1 \%$ level) between the return volatility on expiration and non-expiration days only for the data from the period between March 15, 2013, and May 31, 2015. This can be a confirmation of the thesis formulated by Alkebäck and Hagelin (2004) that price distortions on expiration days may occur during a very short time horizon, so the close-to-close returns might not reflect them properly.

\subsubsection{Event study approach}

Table 9 contains the results of the event study analysis of the volatility effect conducted during the three subperiods. The averages of the abnormal mean deviation of the 5-min returns from the opening to the last hour of continuous trading are presented in Panel 
Table 8 Measures of volatility effect during subperiods

\begin{tabular}{|c|c|c|c|c|c|c|c|c|}
\hline \multicolumn{3}{|c|}{ Subperiod 1} & \multicolumn{3}{|c|}{ Subperiod 2} & \multicolumn{3}{|c|}{ Subperiod 3} \\
\hline $\begin{array}{l}\text { Mean } \\
\text { (in \%) }\end{array}$ & $\begin{array}{l}\text { Median } \\
\text { (in \%) }\end{array}$ & $p$ value & $\begin{array}{l}\text { Mean } \\
\text { (in \%) }\end{array}$ & $\begin{array}{l}\text { Median } \\
\text { (in \%) }\end{array}$ & $p$ value & $\begin{array}{l}\text { Mean } \\
\text { (in \%) }\end{array}$ & $\begin{array}{l}\text { Median } \\
\text { (in \%) }\end{array}$ & $p$ value \\
\hline
\end{tabular}

Panel A: mean deviation of 5-min returns from opening through last hour of continuous trading ${ }^{\mathrm{a}}$

$\begin{array}{cccccccccr}\begin{array}{c}\text { Expiration } \\ \text { days }\end{array} & 0.151 & 0.129 & - & 0.17 & 0.145 & - & 0.156 & 0.139 & - \\ \begin{array}{c}\text { Control } \\ \text { Days I }\end{array} & 0.17 & 0.134 & 0.145 & 0.145 & 0.123 & \mathbf{0 . 0 0 5} & 0.177 & 0.14 & 0.129 \\ \begin{array}{c}\text { Control } \\ \text { Days II }\end{array} & 0.16 & 0.124 & 0.898 & 0.14 & 0.124 & \mathbf{0 . 0 0 6} & 0.153 & 0.141 & 0.894 \\ & & & & & & & & & \end{array}$

Panel B: mean deviation of 5-min returns during last hour of continuous trading

$\begin{array}{cccccccccc}\begin{array}{c}\text { Expiration } \\ \text { days }\end{array} & 0.237 & 0.215 & - & 0.245 & 0.202 & - & 0.236 & 0.198 & - \\ \begin{array}{c}\text { Control } \\ \text { Days I }\end{array} & 0.174 & 0.147 & \mathbf{0} & 0.161 & 0.14 & \mathbf{0} & 0.176 & 0.155 & \mathbf{0} \\ \begin{array}{c}\text { Control } \\ \text { Days II }\end{array} & 0.189 & 0.138 & \mathbf{0} & 0.155 & 0.129 & \mathbf{0} & 0.174 & 0.146 & \mathbf{0} \\ & & & & & & & & & \end{array}$

Panel C: absolute values of returns during overtime

\begin{tabular}{|c|c|c|c|c|c|c|c|c|}
\hline $\begin{array}{l}\text { Expiration } \\
\text { days }\end{array}$ & 0.729 & 0.434 & - & 0.841 & 0.594 & - & 0.648 & 0.469 \\
\hline $\begin{array}{c}\text { Control } \\
\text { Days I }\end{array}$ & 0.306 & 0.234 & 0 & 0.433 & 0.287 & 0 & 0.393 & 0.227 \\
\hline $\begin{array}{l}\text { Control } \\
\text { Days II }\end{array}$ & 0.323 & 0.213 & 0 & 0.382 & 0.279 & 0 & 0.312 & 0.225 \\
\hline$n$ & 130 & & & 148 & & & 185 & \\
\hline
\end{tabular}

This table presents values of means and medians (in percentages) of measures of stock volatility during three subperiods: January 2, 2011, through April 14, 2013 (Subperiod 1); April 15, 2013, through May 31, 2015 (Subperiod 2) and June 1, 2015, through March 31, 2017 (Subperiod 3). In each subperiod, analysis is conducted during three time spans of trading day: from opening to beginning of last hour of continuous trading phase, during last hour of continuous trading, and during overtime. Table presents results for futures expiration days and for two types of control days: first, second, and fourth Fridays of expiration months (Control Days I) and third Fridays of months without futures expiration (Control Days II). Distribution of mean deviation of 5-min returns from opening to last hour of continuous trading, mean deviation of 5-min returns during last hour of continuous trading, and absolute values of returns during overtime are compared between expiration days and control days with use of nonparametric Mann-Whitney $U$ test. $P$ values of test are also presented in table

$p$ values smaller than 0.1 are in bold. Such values indicate that the distribution of the measure differs significantly between expiration days and control days at at least $10 \%$ level

${ }^{\mathrm{a}}$ See Table 6 Footnote a

A of the table. Panel B includes the analogous averages calculated for the returns from the last hour of continuous trading. The measure of volatility included in Panel C of the table is the mean of the abnormal absolute returns from overtime. All of the volatility measures are presented with corresponding values of the $\tau$-grank test statistic.

In the first subperiod (January 2, 2011, through March 14, 2013), there is only one test statistic value from before the last hour of continuous trading that is significantly different from zero (at a $10 \%$ level). It occurs 5 days before expiration; however, it 
Table 9 Event study results for volatility of returns

\begin{tabular}{|c|c|c|c|c|c|}
\hline \multicolumn{2}{|c|}{ Subperiod 1} & \multicolumn{2}{|c|}{ Subperiod 2} & \multicolumn{2}{|c|}{ Subperiod 3} \\
\hline$\overline{\overline{A\left(v^{\prime} l_{t}\right)}}$ & $\overline{\tau-\text { grank }}$ & $\overline{\overline{A\left(\text { volt }_{t}\right)}}$ & $\tau-$ grank & $\overline{\overline{A\left(\text { vol }_{t}\right)}}$ & $\tau-$ grank \\
\hline
\end{tabular}

Panel A: mean deviation of returns from opening through last hour of continuous trading $^{\mathrm{a}}$

$\begin{array}{rrrllrl}-5 & 0.02 & 2.511^{*} & 0.008 & 0.486 & -0.001 & 1.898^{*} \\ -4 & 0.008 & 0.179 & 0.003 & 0.125 & 0.006 & 2.454^{* *} \\ -3 & -0.001 & -0.949 & 0.016 & 1.556 & -0.006 & 1.217 \\ -2 & -0.002 & 0.159 & 0.005 & 0.937 & -0.015 & 0.081 \\ -1 & 0.002 & -0.23 & 0.019 & 2.563^{* *} & -0.001 & 1.459 \\ 0 & -0.001 & -0.099 & 0.032 & 2.747^{* * *} & -0.011 & 1.216 \\ 1 & 0.001 & 0.135 & 0.007 & 1.344 & -0.008 & 0.947 \\ 2 & 0.000 & -0.195 & 0.003 & 0.415 & -0.018 & -0.557\end{array}$

Panel B: mean deviation of returns during last hour of continuous trading

$\begin{array}{rrrrlrr}-5 & 0.002 & 0.982 & -0.003 & 0.092 & 0.009 & 0.952 \\ -4 & 0.001 & -0.277 & 0.023 & 1.716^{*} & 0.004 & 0.907 \\ -3 & 0.012 & 0.946 & 0.011 & 1.577 & 0.004 & 1.193 \\ -2 & -0.009 & -0.719 & 0.004 & -0.044 & -0.002 & 0.244 \\ -1 & 0.009 & -0.256 & 0.04 & 3.25^{* * *} & 0.009 & 1.349 \\ 0 & 0.066 & 5.063^{* * *} & 0.086 & 5.043^{* * *} & 0.068 & 3.35^{* * *} \\ 1 & 0.005 & -0.08 & 0.011 & 0.72 & -0.01 & -0.552 \\ 2 & -0.008 & -0.422 & 0.007 & 0.546 & 0.006 & 0.914\end{array}$

Panel C: absolute returns during overtime

$\begin{array}{lrlrlrl}-5 & -0.066 & -1.496 & -0.049 & 1.249 & 0.054 & 0.887 \\ -4 & 0.007 & -0.189 & 0.322 & 2.703^{* * *} & -0.019 & 0.158 \\ -3 & -0.063 & -1.93^{*} & -0.074 & 0.622 & -0.051 & 0.469 \\ -2 & -0.049 & -1.362 & -0.099 & -1.015 & 0.083 & 0.92 \\ -1 & 0.027 & -0.004 & 0.026 & 2.14^{* *} & 0.308 & 2.935^{* * *} \\ 0 & 0.304 & 4.055^{* * *} & 0.398 & 5.151^{* * *} & 0.214 & 5.345^{* * *} \\ 1 & 0.017 & 0.064 & -0.059 & 0.048 & 0.164 & 0.103 \\ 2 & 0.023 & 0.096 & 0.028 & 1.397 & 0.463 & 2.617^{* *} \\ \mathrm{n} & 130 & & 148 & & 185 & \end{array}$

This table presents results of event study analysis of return volatility conducted during three subperiods: January 2, 2011, through April 14, 2013 (Subperiod 1); April 15, 2013, through May 31, 2015 (Subperiod 2); and June 1, 2015, through March 31, 2017 (Subperiod 3). In each subperiod, analysis in conducted during three time spans of trading day and is employed to mean deviation of 5-min returns from before last hour of continuous trading, mean deviation of 5-min returns during last hour of continuous trading, and to absolute values of returns during overtime. For each day in event window starting from fifth day before expiration and ending on second day after it, average abnormal values of variables are presented with corresponding statistic values

$* * *, * *, *$ denote significance at 1,5 , and $10 \%$ levels, respectively

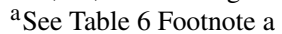


may be not related to futures expiration, as the test statistic values are insignificant on expiration days and on the 4 days preceding expiration. Thus, there is no clear evidence of the impact of futures expiration on return volatility before the last hour of continuous trading during this subperiod. However, during the last hour and overtime on expiration day, the significantly positive test statistics (at a $1 \%$ level) confirm that, during this time span of the expiration day, the volatility of the returns is strongly affected by futures expiration. It can be noticed that three out of the five test statistics computed for the days before expiration on the data from overtime are negative (and one of them is significant-at a $10 \%$ level), suggesting a slight decrease in return volatility during this phase of the trading.

During the second subperiod (March 15, 2013, through May 31, 2015), a significantly higher than expected volatility of the returns can be noticed on the expiration day and on the day before during the whole continuous trading phase and overtime, as there are positive values of the test statistic in Panels A, B, and C (at a 5\% level at least). Some of the test statistics are also significantly positive 4 days before expiration. The impact of futures expiration on return volatility seems to be much stronger during this subperiod than before the implementation of the new transaction system on the WSE on April 15, 2013, so the results are in favor of Conjecture 5.

As with the first subperiod, a similar conclusion can be drawn for the last one (June 1, 2015, through March 31, 2017). On expiration day, the volatility of the returns increases above expectations during both the last hour of continuous trading and overtime. On the day before expiration, the only significantly positive result is the test statistic value computed for the data from overtime. Increased volatility can be noticed during the continuous trading phase before the last hour of trading 4 and 5 days before expiration. As there are fewer significantly positive values before expiration here than during Subperiod 2, we can confirm that the volatility effect of futures expiration weakened after the implementation of the new regulation on the WSE concerning short selling (as was assumed in Conjecture 6). A significantly positive mean abnormal absolute value of the returns during overtime on day $t=2$ was also detected in the research conducted for the data from the whole period of 2011-2017 (as presented in Table 5). This more detailed study reveals that the significance appears only in the data from the last two researched years. It was difficult for the authors to find the reason for this significance; however, as it occurs after expiration, we suppose that it is connected with some confounding events rather than with futures expiration.

Comparing the results of the event study presented in Tables 5 and 9, it can be noticed that the rise in volatility was detected on most of the days before expiration during the first part of the study. However, further and more-detailed research indicated that this growth appeared mostly during the second period (that is, between March 15, 2013, and May 31, 2015). In the following final section, we will summarize the results of our research (with respect to the conjectures formulated in Sect. 3.3 in particular).

\subsection{Entire stock market on expiration days: brief summary of volatility effect}

At the end of the research, it should be mentioned that most of the futures contracts listed on the world exchanges expire quarterly (on the same days as the futures on the 
WSE). Thus, the detected effects may at least partially come from the influence that the situation on foreign markets has on the Polish stock market. In this context, the behavior of the entire market system on expiration days should be examined.

As the Polish stock market is under the influence of the American market and the major futures in the U.S. (especially S\&P 500 futures) also expire on quarterly Fridays, some intraday variation in the time series of stock prices and volumes on the WSE could be potentially caused by these American futures expirations. The abovementioned U.S. contracts are settled at the opening prices of the underlying index. As the U.S. market opens at 3:30 PM in the Central European Time Zone, potential disturbances in the stock quotes should be visible around this time. A visual inspection of the figures of trading volume and volatility do not reveal such an impact. On expiration days, the trading volume of the underlying stocks increases almost linearly until the last hour of listing. The plots of volatility do not indicate any significant increase after 3:30 PM (i.e., after the opening of the U.S. market). Moreover, foregoing studies from different world markets reveal that expiration-day effects appear mainly on emerging markets, while they do not occur on developed markets (see, e.g., Illueca and Lafuente (2006), who compare S\&P 500 futures and Ibex 35 futures in this context) or are negligible (Stoll and Whaley 1991). This fact leads us to conclude that the effects we detected came from the expirations of domestic futures.

To confirm this thesis, we conducted research on four stock indices; namely, the WIG, WIG20, mWIG40, and sWIG80. ${ }^{1}$ Having access to the 5-min returns of the indices from the time period of January 2012 through December 2017, we analyzed the volatility of the returns during this time span in an analogous way as we did for the stocks. Determining the subperiods of a day, we additionally separated the first window (from the opening to the beginning of the last hour of continuous trading) into two parts: before the opening of the American market, and after it. Detailed results from the analysis are not included in the article but can be provided by the authors upon request.

The volatility of the returns of the WIG and WIG20 indices was higher on expiration days than on control days, both during the last hour of continuous trading and overtime. An event study analysis revealed that this was also higher than expected. The growth of volatility on the WIG20 index during the last hour of continuous trading probably came from the expiration of futures on the WIG20 index, while this was caused by stock futures expirations during overtime, as most of the stocks that set the underlying assets of the stock futures that comprise the WIG20 index. As the stocks from WIG20 index have the majority of shares in the WIG index, these two indices behave similarly. Before the last hour of trading, there was no rise in the volatility of these indices, even after the opening of the U.S. market. This confirms that the expiration of US S\&P 500 futures had no impact on the volatility of the WSE stocks and that the WSE reacted to the opening of the American market as usual.

The analysis of the mWIG40 returns revealed that the volatility of the index on expiration days was higher than on control days and was also higher than expected

\footnotetext{
1 The WIG index is comprised of all companies listed on the WSE Mail List. The WIG20 index is based on the value of the portfolios with shares in the 20 major and most-liquid companies. The mWIG40 index is comprised of 40 medium-sized companies listed on the WSE Mail List. The sWIG80 index is based on 80 smaller companies listed on the WSE (excluding WIG20 and mWIG40 participants).
} 
mostly during the last hour of continuous trading. This result is in line with our expectations, as the futures on the mWIG40 expire on the same days as futures on stocks and futures on the WIG20; their final settlement prices are calculated as the average of the values of the continuous trading of the index from the last hour of trading and the value at close.

Starting after the trading session on March 21, 2014, the calculation of the sWIG80 index was discontinued until the beginning of 2015; thus, the analysis of this index's returns was conducted on the data from two subperiods: from January 2012 through March 21, 2014, and from January 2015 through December 2017. The results indicated that, during each of the time intervals of expiration days, the volatility of the index did not differ from the volatility calculated on control days and was not higher than during the analogous subperiods of the days preceding expiration. This suggests that stocks from the sWIG80 index (whose prices have no impact on the final settlement prices of the futures listed on the WSE) were not influenced by these futures expirations.

The results discussed above confirm the thesis that the stocks that set the underlying assets of the futures or that are comprised of the underlying indices were affected by the futures expirations. The rise in the volatility of indices' returns was visible mainly during the subperiods of the expiration days from which the returns were used in calculating the final settlement prices of the futures. Our analysis did not detect any additional influence of American S\&P 500 expirations on the situation of the WSE.

\section{Conclusions}

The research on the volume and volatility effects of stock futures expirations on the Warsaw Stock Exchange confirms the existence of the effects during the period under study. The results of the paper are compatible with the findings of the studies on this topic based on daily data by Suliga and Wójtowicz (2019). The high-frequency data employed in this study additionally allows us to determine the moment of the day when the trading activity of investors significantly increases and when the effects are the strongest.

The study reveals that trading volume as well as the turnover value of stocks that set the underlying assets of futures are significantly higher on expiration days than on other Fridays, and they are also higher than on the days before expiration (especially during both the last hour of continuous trading and overtime). The event study analysis indicates that these two variables are also higher than usual on a trading day preceding expiration. This suggests that the increased trading activity of investors starts 1 day before expiration.

The results obtained for the data from the whole period under study (2011-2017) also provide strong evidence of the volatility effect. During both the last hour of continuous trading and overtime, return volatility is significantly higher on expiration Fridays than on other Fridays. Similar to the case of the volume effect, the volatility effect is detected 1 day before expiration, as volatility is higher than normal on the whole continuous trading phase on this day. On expiration Fridays, the volatility of the returns increases below expectations during both the continuous trading phase and overtime. 
The above-mentioned results confirm Conjectures 1 through 4; in particular, they confirm the observations from other markets that the effects especially occur during this period of the trading day from which the final settlement prices of futures are calculated (see, e.g., Stoll and Whaley 1986; Illueca and Lafuente 2006; Morawska 2007; Fung and Jung 2009; Chow et al. 2013; and Agarwalla and Pandey 2013). The plots of the cumulated turnover values and 5-min absolute returns reveal that the trading activity and volatility increase first during the last hour of continuous trading, so this is during the time of determining the settlement price of the futures on the WIG20 index. As most of the stocks that are underlying assets of stock futures constitute the WIG20 index, these effects are probably related to the activity of investors with opened positions in index futures. An additional spurt of trading volume and volatility occurs during overtime. This most likely comes from the fact that the stock futures settlement price is equal to the stock price at closing, so investors with opened positions in the stock futures try to influence the closing price when they are placing orders for closing.

An additional analysis of the volatility of indices returns (which results are briefly summarized in the article) suggests that, during the period under study, only the returns of those stocks whose prices influenced futures settlement prices were affected by futures expirations and that the expirations of the American S\&P 500 futures had no impact on the volatility of the stocks listed on the WSE.

In order to check whether the impact of futures expirations on stocks changed over time, the whole period under study was divided into three subperiods. In each of them, both of the researched effects were detected, as increased turnover value and increased volatility occurred on expiration days during the last hour of continuous trading and overtime. However, the effects were strongest during the second subperiod (between March 15, 2013, and May 31, 2015). Only during this subperiod on the day before expiration were the turnover values and return volatility significantly higher than expected during each of the trading phases. These observations are in line with Conjectures 5 and 6. After the implementation of the new transaction system on the WSE on March 15, 2013, the futures expiration effects intensified, but the introduction of the changes in the rules regarding the short selling of stocks that took place on June 1, 2015, seems to have attenuated them. However, as during both the last hour of trading and overtime on expiration days, the effects were detected in all of the researched subperiods; therefore, Conjectures 5 and 6 can only be partially confirmed. An intensification of the effects during the second subperiod is revealed mainly in the early appearance of the effects - on the day before expiration and on the expiration day before the last hour of continuous trading. The reduction of the effects during the last subperiod is related to the lack of the effects on Thursdays preceding expiration Fridays (except for the volatility above expectations during overtime) as well as their lack on expiration days before the last hour of continuous trading.

The need to change the way stock futures contracts are settled on the WSE remains an open question. As the occurrence of expiration-day effects was confirmed, the extension of the settlement period should be taken into account. However, the conducted research did not include the price reversal effect, whose occurrence and strength could be a key factor that determines the need for such a change. Further research will be directed towards this effect as well as towards a comparison of the results from the studies on all three expiration-day effects on the WSE, with analogous results based 
on the high-frequency data for advanced stock markets (e.g., the German stock market or London stock market where stocks of some Polish companies are listed). However, further research depends on the availability of intraday data for the respective stock markets.

The dependency between stock market and futures market can potentially result in other phenomena (e.g., an increase in the volatility of underlying stock prices after the implementation of new futures contracts). Detecting these along with a detailed analysis of the interdependencies between the markets will be interesting subjects for future investigations.

Acknowledgements We would like to thank the anonymous referees for their valuable comments on earlier versions of this paper. We also thank the Warsaw Stock Exchange for providing the intraday data. This publication was financed by AGH University of Science and Technology in Krakow (institutional subsidy for maintaining Research Capacity Grant 11111.200.325).

Open Access This article is distributed under the terms of the Creative Commons Attribution 4.0 International License (http://creativecommons.org/licenses/by/4.0/), which permits unrestricted use, distribution, and reproduction in any medium, provided you give appropriate credit to the original author(s) and the source, provide a link to the Creative Commons license, and indicate if changes were made.

\section{References}

Agarwalla SK, Pandey A (2013) Expiration-day effects and the impact of short trading breaks on intraday volatility: evidence from the Indian market. J Futur Mark 33(11):1046-1070

Alkebäck P, Hagelin N (2004) Expiration day effects of index futures and options: evidence from a market with a long settlement period. Appl Financ Econ 14(6):385-396

Bollen NPB, Whaley RE (1999) Do expiration of Hang Seng Index derivatives affect stock market volatility? Pac Basin Finance J 7:453-470

Chamberlain TW, Cheung SC, Kwan CCY (1989) Expiration-day effects of index futures and options: some Canadian evidence. Financ Anal J 45(5):67-71

Chay JB, Kim S, Ryu H (2013) Can the indicative price system mitigate expiration-day effects? J Futur Mark 33(10):891-910

Chen C, Williams J (1994) Triple-witching hour, the change in expiration timing, and stock market reaction. J Futur Mark 14:275-292

Chow Y, Yung H, Zhang H (2003) Expiration day effects: the case of Hong Kong. J Futur Mark 23:67-86

Chow EH, Hung C, Liu CS, Shiu C (2013) Expiration day effects and market manipulation: evidence from Taiwan. Rev of Quant Finance Acc 41:441-462

Corredor P, Lechón P, Santamaría R (2001) Option-expiration effects in small markets: the Spanish stock exchange. J Futur Mark 21:905-928

Day TE, Lewis CM (1988) The behaviour of the volatility implicit in the prices of stock index options. J Financ Econ 22:103-122

Debasish SS (2010) Investigating expiration day effects in stock index futures in India. J Econ Behav Stud $1: 9-19$

Diz F, Finucane TJ (1998) Index option expirations and market volatility. J Financ Eng 7:1-23

Drogota V, Tilica VC (2014) Market efficiency of the post-communist east European stock markets. Cent Eur J Oper Res 22(2):307-337

Feinstein SP, Goetzmann WN (1988) The effect of the "triple witching hour" on stock market volatility. Econ Rev Fed Bank Atlanta 73(5):2-18

Fung JKW, Jung HHM (2009) Expiration-day effects—an Asian twist. J Futur Mark 29:430-450

Gurgul H, Majdosz P (2007) The informational content of insider trading disclosures: empirical results for the Polish stock market. Cent Eur J Oper Res 15(1):1-19

Hancock GD (1993) Whatever happened to the triple witching hour? Financ Anal J 49(3):66-72 
Herbst AF, Maberly ED (1990) Stock index futures, expiration day volatility, and the "Special" friday opening: a note. J Futur Mark 10(3):323-325

Hsieh WG (2009) Expiration-day effects on individual stocks and the overall market: evidence from Taiwan. J Futur Mark 29(10):920-945

Hsieh WG, Ma T (2009) Expiration-day effects: does settlement price matter? Int Rev Econ Finance 18:290-300

Illueca M, Lafuente JÁ (2006) New evidence on expiration-day effects using realized volatility: an intraday analysis for the Spanish stock exchange. J Futur Mark 26:923-938

Karolyi GA (1996) Stock market volatility around expiration days in Japan. J Deriv 4(2):23-43

Kolari J, Pynnönen S (2001) Nonparametric rank tests for event studies. J Empir Finance 18:953-971

Lien D, Yang L (2005) Availability and settlement of individual stock futures and options expiration-day effects: evidence from high-frequency data. Q Rev Econ Finance 45:730-747

Mahalwala R (2016) A study of expiration-day effects of index derivatives trading in India. Metamorphosis J Manag Res 15(1):10-19

Morawska H (2004) Wpływ efektu trzech wiedźm na okresowe kształtowanie się cen instrumentu bazowego. Zeszyty Naukowe Uniwersytetu Szczecińskiego. Finanse. Rynki finansowe. Ubezpieczenia 2(2):403-416

Morawska H (2007) Wpływ dnia wygaśnięcia indeksowych kontraktów terminowych i opcji na rynek kasowy GPW w Warszawie SA. In: Gabryelczyk K, Ziarko-Siwek U (eds) Inwestycje Finansowe. CeDeWu, Warszawa

Murg M, Pachler M, Zeitlberger ACM (2016) The impact of analyst recommendations on stock prices in Austria (2000-2014): evidence from a small and thinly traded market. Cent Eur J Oper Res 24(3):595-616

Narang S, Vij M (2013) Long-term effects of expiration of derivatives on Indian spot volatility. ISRN Econ 2013:1-6

Pope PF, Yadav PK (1992) The impact of option expiration on underlying stocks: the UK evidence. J Bus Finance Acc 19:329-344

Schlag C (1996) Expiration day effects of stock index derivatives in Germany. Eur Financ Manag 2(1):69-95

Stoll HR, Whaley RE (1986) Expiration day effects of index options and futures. Monograph series in finance and Econ, monograph 1986-3. New York University, New York

Stoll HR, Whaley RE (1987) Program trading and expiration-day effects. Financ Anal J 43(2):16-28

Stoll HR, Whaley RE (1990) Program trading and individual stock returns: ingredients of the triple-witching brew. J Bus 63(1):165-192

Stoll HR, Whaley RE (1991) Expiration-day effects: what has changed? Financ Anal J 47(1):58-72

Stoll HR, Whaley RE (1997) Expiration-day effects of the all ordinaries share price index futures: empirical evidence and alternative settlement procedures. Aus J Manag 22(22):139-174

Suliga M (2017) Price reversal as potential expiration day effect of stock and index futures: evidence from Warsaw Stock exchange. Manag Econ 18(2):201-225

Suliga M, Wójtowicz T (2019) Expiration-day effects of stock and index futures on the Warsaw Stock Exchange. Bank Credit (accepted)

Tripathy N (2010) Expiration and week effect: empirical evidence from the indian derivative market. Int Rev Bus Res Pap 6(4):209-219

Vipul V (2005) Futures and options expiration-day effects: the Indian evidence. J Futur Mark 25(11):1045-1065

$\mathrm{Xu}$ C (2014) Expiration-day effects of stock and index futures and options in Sweden: the return of the witches. J Futur Mark 34(9):868-882

Publisher's Note Springer Nature remains neutral with regard to jurisdictional claims in published maps and institutional affiliations. 